\title{
The Role of Octopamine and Tyramine in Drosophila Larval Locomotion
}

\author{
Mareike Selcho, ${ }^{1,2 *}$ Dennis Pauls, ${ }^{1,2}$ Basil el Jundi, ${ }^{3}$ Reinhard F. Stocker, ${ }^{1}$ and Andreas S. Thum \\ 'Department of Biology, University of Fribourg, Fribourg, Switzerland \\ ${ }^{2}$ Department of Biology, Philipps-University Marburg, Marburg, Germany \\ ${ }^{3}$ Department of Biology, Lund University, Lund, Sweden
}

\section{ABSTRACT}

The characteristic crawling behavior of Drosophila larvae consists of a series of rhythmic waves of peristalsis and episodes of head swinging and turning. The two biogenic amines octopamine and tyramine have recently been shown to modulate various parameters of locomotion, such as muscle contraction, the time spent in pausing or forward locomotion, and the initiation and maintenance of rhythmic motor patterns. By using mutants having altered octopamine and tyramine levels and by genetic interference with both systems we confirm that signaling of these two amines is necessary for larval locomotion. We show that a small set of about 40 octopaminergic/tyraminergic neurons within the ventral nerve cord is sufficient to trigger proper larval
\end{abstract}

locomotion. Using single-cell clones, we describe the morphology of these neurons individually. Given various potential roles of octopamine and tyramine in the larval brain, such as locomotion, learning and memory, stressinduced behaviors or the regulation of the energy state, functions that are often not easy to discriminate, we dissect here for the first time a subset of this complex circuit that modulates specifically larval locomotion. Thus, these data will help to understand-for a given neuronal modulator-how specific behavioral functions are executed within distinct subcircuits of a complex neuronal network.

INDEXING TERMS: Drosophila larva; locomotion; single cell analysis; octopamine; tyramine

Locomotor activity is an integrative characteristic of the functional state of the nervous system, as it is implicated directly or indirectly in most kinds of behaviors such as foraging or mating. In adult Drosophila, distinct brain structures like the mushroom bodies or the central complex have been shown to be required for the control of locomotor activity (Strauss and Heisenberg, 1993; Martin et al., 1998). In Drosophila larvae, the central complex precursors seem to be involved in locomotion (Varnam et al., 1996), while the role of the mushroom bodies has not been investigated in detail. Larval crawling consists of characteristic series of rhythmic peristaltic waves interrupted by episodes of head swinging and turning, which represent the searching and decision-making behavior (Wang et al., 1997; Suster et al., 2004; Lahiri et al., 2011).

In vertebrates, epinephrine and norepinephrine are essential in the modulation of different behaviors, whereas in invertebrates this task appears to be accomplished by octopamine (OA) and tyramine (TA) (Roeder,
2005). OA and TA have been shown to act in the adaptation of neuronal networks to environmental changes. In combination with neuropeptides, these amines regulate a diverse range of physiological, cellular and behavioral processes (Roeder, 1999, 2005; Roeder et al., 2003; Nässel and Winther, 2010). OA, for example, may alter

\footnotetext{
${ }^{*}$ Current address for Mareike Selcho and Dennis Pauls: Neurobiology and Genetics, Theodor-Boveri Institute, Biocenter, University of Würzburg, Würzburg, Germany.

${ }^{*}$ Current address for Andreas S. Thum: Department of Biology, University of Konstanz, Konstanz, Germany

The first two authors contributed equally to this work.

Grant sponsor: Swiss National Funds; Grant numbers: PBFRP3-133515 (to M.S.), PBFRP3-133659 (to D.P.), 31003A-105517 (to R.F.S.), 31003A132812 (to A.S.T.); Grant sponsor: Deutsche Forschungsgemeinschaft; Grant number: TH1584/1-1 (to A.S.T.).

${ }^{*}$ CORRESPONDENCE TO: Mareike Selcho, University of Würzburg, Neurobiology and Genetics, Theodor-Boveri Institute, Biocenter, Am Hubland, D-97074 Würzburg, Germany.

E-mail: mareike.selcho@uni-wuerzburg.de
} 
the insects' sensory pathways by modulating receptor sensitivity or receptor density or by affecting neurotransmitter release via presynaptic receptors (Farooqui, 2007). OA has also been shown to be involved in the modulation of a wide variety of behaviors. For instance, the stimulation of a single dorsal unpaired median neuron in the locust revealed a role of $O A$ in the modulation of neuromuscular potentials and the tension of tibial muscles, indicating an adaptation of motor function to environmental changes (Evans and O'Shea, 1977; Evans, 1984). In Drosophila, OA was reported to act directly in the hemolymph, providing energy from the fat body for stress-dependent behaviors, such as fight-or-flight responses, which in vertebrates are regulated by the adrenergic system (Roeder, 2005). Finally, in fruit flies OA may modulate aggression, sleep, egg-laying behavior, learning and memory, and even ethanol tolerance (Monastirioti et al., 1996; Baier et al., 2002; Schwärzel et al., 2003; Scholz, 2005; Scholz et al., 2005; Schroll et al., 2006; Certel et al., 2007; Hoyer et al., 2008; Crocker et al., 2010).

TA was initially considered to be just an intermediate product of OA synthesis from tyrosine, lacking any distinct biological function. Later on, the identification of a TA receptor in the Drosophila genome suggested an independent role of this amine as a signaling molecule (Arakawa et al., 1990; Saudou et al., 1990). Evidence for this was provided by the hypomorphic TA receptor mutant honoka (Saudou et al., 1990; Arakawa et al., 1990; Kutsukake et al., 2000) and more recently by the $T d c 2^{R O 54}$ mutant (tyrosine decarboxylase, the enzyme necessary for the rate-limiting step in OA biosynthesis), which lacks both OA and TA (Schüpbach and Wieschaus, 1991; Cole et al., 2005; Hardie et al., 2007). Compared to wildtype flies, honoka shows a complete lack of inhibition of the evoked excitatory junction potentials (EJP). In contrast to the excitatory effect of OA, TA reduces muscle contraction due to the inhibitory effect of EJPs on the body wall muscles (Kutsukake et al., 2000; Nagaya et al., 2002). Hence, with respect to muscle contraction, OA and TA act as antagonists. Regarding larval locomotion, Saraswati and colleagues showed that $T B H$ mutant larvae, characterized by increased levels of TA and the lack of OA, illustrated reduced forward locomotion, displayed by more direction changes greater than $20^{\circ}$, compared to wildtype larvae (Monastirioti et al., 1996; Saraswati et al., 2004). Feeding OA or yohimbine, an antagonist of the TA receptor, was sufficient to rescue this phenotype at least partially, while a combinatorial feeding of both agents ended up in mutants crawling even better (Saraswati et al., 2004). Based on these results, Saraswati and colleagues suggested an oppositional role of OA and TA in larval locomotion, because both OA and yohim- bine had similar effects, whereas the combinatorial stimulation was even more effective. This assumption is supported by the fact that TA feeding further degraded forward locomotion in T $B H$ mutant larvae. Moreover, feeding TA was able to reverse the behavioral rescue by $\mathrm{OA}$ feeding (Saraswati et al., 2004). Thus, the combinatorial role of both biogenic amines is necessary for normal larval locomotion. Interestingly, no locomotor phenotype in adult $T \beta H$ mutants has been found yet, while mutant flies lacking both $\mathrm{OA}$ and TA show defective locomotion behavior (Homyk and Sheppard, 1977; O'Dell, 1988; Schüpbach and Wieschaus, 1991; Cole et al., 2005; Hardie et al., 2007). Additionally, decapitated flies responded to OA or TA added to the exposed nerve cord with a significant stimulation of locomotion (Yellman et al., 1997).

Immunohistochemical reports showed that $O A$ is mainly synthesized in the unpaired median (UM) neurons of insects whose cell bodies are located either ventrally (VUM neurons) or dorsally (DUM neurons) in the subesophageal ganglion (SOG) and ventral nerve cord (VNC). Moreover, it was shown that UM neurons of the thoracic ganglion send efferents to most organs and muscles, while those of the SOG innervate almost all neuropils of the brain (Bräunig, 1991; Sinakevitch and Strausfeld, 2006; Vömel and Wegener, 2008; Busch et al., 2009).

Neurons expressing both OA and TA in larval and adult Drosophila were characterized mostly in the brain (Monastirioti et al., 1995; Python and Stocker, 2002; Cole et al., 2005; Sinakevitch and Strausfeld, 2006; Busch et al., 2009); only a few reports refer to those of the VNC (Monastirioti et al., 1996; Nagaya et al., 2002; Cole et al., 2005; Vömel and Wegener, 2008). Tdc2-positive neurons in the VNC projecting to the periphery were described in Drosophila larva (Vömel and Wegener, 2008). Here, we additionally describe the arborization pattern of single VNC cells. Muscle efferent OA/TA cells of the abdominal ganglion broadly innervate most of the muscles of their segment. Larval muscles 6 (VL3 and other terms below in parentheses according to Bate, 1993), 7 (VL4), and potentially 28 (VO3) are devoid of type II endings and therefore seem to lack octopaminergic/tyraminergic input, while all other muscle fibers seem to receive combined signaling (Monastirioti et al., 1995; Hoang and Chiba, 2001).

In this study we revisited the role of OA and TA in larval locomotion in more detail. We confirm their implication in this behavior, postulated by Saraswati and colleagues, by using mutants that lack either OA $(T \beta H)$, both $O A$ and TA $\left(T d c 2^{R O 54}\right)$, or exhibit TA receptor defects (honoka). Using different lines characterized by distinct modifications in the balance of OA and TA levels allowed us to expand the studies of Saraswati and colleagues in detail, as they focused on pharmacological treatment in $T \beta H$ mutants to 
TABLE 1.

Primary Antibodies

\begin{tabular}{|c|c|c|c|c|}
\hline Antibody & Host & Immunogen & Manufacturer & $\begin{array}{l}\text { Working } \\
\text { dilution }\end{array}$ \\
\hline Anti-GFP & $\begin{array}{l}\text { Rabbit, polyclonal } \\
\text { serum }\end{array}$ & $\begin{array}{l}\text { Purified green fluorescent protein } \\
\text { (GFP), a } 27-\mathrm{kDa} \text { protein derived } \\
\text { from the jellyfish Aequorea } \\
\text { victoria }\end{array}$ & $\begin{array}{l}\text { A6455, Molecular Probes } \\
\text { (Eugene, OR) }\end{array}$ & $1: 1,000$ \\
\hline Chicken anti-GFP & Chicken, polyclonal & $\begin{array}{l}\text { Recombinant GFP containing a } \\
\text { 6-his tag }\end{array}$ & $\begin{array}{l}\text { AB16901, Chemicon } \\
\text { (Temecula, CA) }\end{array}$ & $\begin{array}{l}1: 150 \\
1: 170\end{array}$ \\
\hline ChAT4B1 & Mouse, monoclonal & $\begin{array}{l}\text { 80-kDa Drosophila Choline } \\
\text { acetyltransferase protein }\end{array}$ & $\begin{array}{l}\text { ChAT4B1, DSHB } \\
\text { (lowa City, IA) }\end{array}$ & $1: 100$ \\
\hline 1D4 anti-Fasciclin II & Mouse, monoclonal & $\begin{array}{l}\text { Bacterially expressed fusion } \\
\text { peptide containing the intracellular } \\
\text { C-terminal } 103 \text { amino acids of } \\
\text { the PEST transmembrane form of Fasll }\end{array}$ & 1D4, DSHB (lowa City, IA) & $1: 55$ \\
\hline $3 C 11$ & Mouse, monoclonal & $\begin{array}{l}\text { First open reading frame of the } \\
\text { Drosophila Synapsin protein }\end{array}$ & Klagges et al., 1996 & $1: 50$ \\
\hline $\mathrm{T} \beta \mathrm{H}$ & Rat, polyclonal & $\begin{array}{l}\text { A bacterially expressed purified } \\
\text { internal part of the protein } \\
\text { (Sal-Xho fragment) }\end{array}$ & Monastirioti et al., 1996 & $1: 75$ \\
\hline Anti-p-Tyramine & Rabbit, polyclonal & $\begin{array}{l}\text { p-Tyramine-gluteraldehyde- } \mathrm{N} \text {-alpha-acetyl- } \\
\text { L-lysine- } \mathrm{N} \text {-methylamide }\end{array}$ & $\begin{array}{l}\text { AB124, Chemicon, } \\
\text { (Temecula, CA) }\end{array}$ & $1: 200$ \\
\hline $\begin{array}{l}\text { Anti-conjugated } \\
\text { octopamine }\end{array}$ & Rabbit, polyclonal & Octopamine-glutaraldehyde-carriers & $\begin{array}{l}\text { 1003GE, MoBiTec } \\
\text { (Göttingen) }\end{array}$ & $1: 200$ \\
\hline
\end{tabular}

study the role of OA and TA. In line with previous reports, we demonstrate that the lack of $\mathrm{OA}$ or the ablation of efferent OA/TA cells in the entire central nervous system (CNS) leads to severe locomotor defects. Moreover, we confirm that modified levels of TA result in enhanced locomotion causing hyperactivity. In our study, to our knowledge for the first time, we specifically restrict the locomotor effect to the OA/TA neurons within the VNC and describe the morphology of these neurons at the single-cell level. Our bipartite anatomical and behavioral approach provides new insights into the potentially antagonistic roles of $O A$ and $T A$ in larval locomotion.

\section{MATERIALS AND METHODS}

\section{Fly strains}

Fly strains were reared on standard Drosophila medium at $25^{\circ} \mathrm{C}$ or $18^{\circ} \mathrm{C}$ with a $14 / 10$ hours light/dark cycle. For behavioral experiments $T \beta H^{n M 18}, T d c 2^{R O 54}$, and honoka $(\mathrm{w}[1118] ; \mathrm{P}\{\mathrm{w}[+\mathrm{mW} \cdot \mathrm{hs}]=\mathrm{IwB}\}$ TyrR[hono]) mutants were analyzed (Schüpbach and Wieschaus, 1991; Monastirioti et al., 1996; Kutsukake et al., 2000; Cole et al., 2005). UAS-hid, rpr (Kurada and White, 1998) on the X-chromosome was used as an effector to ablate defined neurons by crossing to the Gal4-driver line Tdc2-Gal4 (Cole et al., 2005). Heterozygous controls were obtained by crossing Gal4-driver and UAS-effector to $w^{1118}$. To restrict $T d c 2$ Gal4 expression to the brain and SOG, flies were recombined with tshGal80 (Shiga et al.; 1996; Clyne and Miesenböck, 2008); kindly provided by J. Simpson (HHMI,
Janelia Farm, Ashburn, VA), thus inhibiting Gal4 expression in the VNC. For visualizing neurons, we crossed $T d c 2-G a \mid 4$ or Tdc2-Gal4;tshGal80, respectively, with UASmCD8::GFP or UAS-Cameleon2.1 (Lee and Luo, 1999; Diegelmann et al., 2002). UAS-Cameleon2. 1 was shown to give a stronger signal than UAS-mCD8::GFP ((Selcho et al., 2009), data not shown for $T d c 2-G a l 4)$. For single-cell staining, $y$ w hsp $70-f l p ; S p / C y O$; UAS> CD2y $>$ mCD8::GFP/TM6b (Struhl and Basler, 1993; Wong et al., 2002); kindly provided by Gary Struhl (Columbia University, New York, NY) virgins were crossed to Tdc2-Gal4 or Tdc2-Gal4;Tdc2-Gal4 males. A single heat shock was applied by placing vials containing eggs or larvae in a water bath at $37^{\circ} \mathrm{C}$ for 17.5 minutes. For the onset of heat shock, we chose different times from 0 to 200 hours after egg laying.

\section{Immunofluorescence Immunostaining}

Preparation of the CNS (filets for the muscle innervations) of third instar larvae were done in phosphate-buffered saline (PBS, pH 7.4). The CNS and filets were then fixed in 3.6\% formaldehyde (Merck, Darmstadt, Germany) or $4 \%$ paraformaldehyde (Merck), respectively, in PBS for 35 minutes, washed in PBT (PBS with $3 \%$ Triton-X 100 , Sigma-Aldrich, St. Louis, MO), and blocked with $5 \%$ normal goat serum (NGS; Vector Laboratories, Burlingame, CA) in PBT. Specimens were incubated with the primary antibodies (Table 1) in blocking solution at least for 1 night at 
$4^{\circ} \mathrm{C}$. Preparations were washed six times with PBT and incubated for 1 night at $4{ }^{\circ} \mathrm{C}$ with the secondary antibodies. Finally, specimens were rinsed six times in PBT and mounted in Vectashield (Vector Laboratories) in PBS. Until scanning, specimens were stored in darkness at $4^{\circ} \mathrm{C}$.

To detect $O A$ and TA we used a modification of the staining protocol of Sinakevitch and Strausfeld (2006; Busch et al., 2009). Third instar larvae were put on ice for at least 1 hour before being prefixed with opened cuticle for 5 minutes in $0.65 \%$ glutaraldehyde (in $0.1 \mathrm{M}$ sodium cacodylate buffer; 214971000, Acros Organics, Geel, Belgium) with $1 \%$ sodium metabisulfite (SMB, S1516, Sigma-Aldrich). Then the CNS was removed and fixed at room temperature. After 40 minutes the specimens were rinsed four times in TrisHCL SMB $(0.05 \mathrm{M}$ Tris $\mathrm{HCL} 0.45 \% \mathrm{SMB}$ ), treated for 30 minutes with $0.3 \%$ sodium borohydride (189301000, Acros Organics) in TrisHCL SMB, and rinsed again four times in Tris $\mathrm{HCL}$ SMB and two times in TrisHCL SMB TX (TrisHCL SMB containing $0.3 \%$ Triton-X 100). Specimens were blocked for 1.5 hour in 10\% NGS in TrisHCL SMB TX. After at least 2 nights at $4{ }^{\circ} \mathrm{C}$ in blocking solution containing the primary antibodies, specimens were rinsed six times with TrisHCL TX. The secondary antibodies in $5 \%$ NGS solution were incubated for 2 nights at $4^{\circ} \mathrm{C}$. After washing five times in TrisHCL TX and two times in TrisHCL, preparations were mounted in Vectashield (Vector Laboratories).

\section{Antibodies}

To visualize the total expression pattern of $T d c 2-G a l 4$ and the innervation patterns of single Tdc2-Gal4-positive neurons, we applied a polyclonal serum against green fluorescent protein (anti-GFP, A6455, Molecular Probes, Eugene, OR; 1:1,000; Table 1) in combination with two different mouse antibodies labeling the neuropil (anti-ChAT, ChAT4B1, anti-Cholineacetyltransferase; DSHB, lowa City, IA; 1:100; Table 1) and axonal tracts (anti-FasII, 1d4, antiFasciclin II; DSHB; 1:55; Table 1), respectively. The muscle arborizations of $T d c 2-G a l 4$ cells were shown by anti-GFP in combination with a monoclonal mouse antibody against synapsin (anti-Synapsin, 3C11, Klagges et al., 1996; kindly offered by E. Buchner, University of Würzburg, Germany; 1:50; Table 1). anti-GFP with an antibody against tyramine $\beta$-hydroxylase produced in rats (anti-T $\beta H$; Monastirioti et al., 1996; kindly provided by M. Monastirioti, IMBB, FORTH, Greece; 1:75; Table 1) was used to see whether all $T d c 2$-Gal4-positive neurons are octopaminergic. OA and TA were labeled via a polyclonal antibody against glutaraldehyde-coupled OA (anti-OA, \#1003GE, MoBiTec, Göttingen, Germany; 1:200; Table 1) or a polyclonal antibody against glutaraldehyde-coupled p-TA (anti-TA, AB124, Chemicon International, Temecula, CA; 1:200; Table 1) in combination with a chicken anti-GFP antibody
(anti-GFPch, AB16901, Chemicon; 1:150 and 1:170; Table 1). As secondary antibodies, goat anti-rabbit IgG Alexa Fluor 488 (A11008, Molecular Probes, 1:200), goat anti-rat IgG Alexa Fluor 568 (A11077, Molecular Probes; 1:200), fluorescein (FITC)-conjugated donkey anti-chicken (703-095-155, Jackson ImmunoResearch, West Grove, PA; 1:150), goat anti-rabbit IgG DyLight 488 (111-486-003, Jackson; 1:250), Сy3 goat anti-rabbit IgG (111-165-003, Jackson; 1:100), Cy3 goat anti-mouse IgG (A 10521, Molecular Probes, 1:100 or 115-166-003, Jackson; 1:250) were used.

\section{Antibody characterization Anti-GFP}

The rabbit anti-GFP antibody gave the same staining pattern in the VNC of the Tdc2-Gal4/ UAS-Cameleon2.1 larvae as the anti-GFP antibody produced in chicken. Additionally, staining was not observed in VNCs of larvae expressing only Tdc2-Gal4 or only UAS-Cameleon2.1 (data not shown).

\section{Chicken anti-GFP}

The anti-GFPch antibody detects a band of a molecular weight around $30 \mathrm{kDa}$ in lysates prepared from E. coli expressing GFP on western blot. No band was detected in lysates of $E$. coli that do not express GFP.

\section{ChAT4B1}

The anti-ChAT antibody was shown to label a single band at a position of about $80 \mathrm{kDa}$ in crude fly head samples (Takagawa and Salvaterra, 1996).

\section{4 anti-Fasciclin /I}

The anti-Fasll antibody labeled a $97 \mathrm{kDa}$ band in western blot, which was gone in Fasll null mutants (Grenningloh et al., 1991; Mathew et al., 2003). The staining pattern observed in this study is identical to previous reports (Grenningloh et al., 1991; Landgraf et al., 2003; Mathew et al., 2003).

\section{$3 \mathrm{C} 11$}

The anti-synapsin antibody recognizes multiple synapsin isoforms, shown on western blots with Drosophila heads. The bands were gone in the deletion mutant (Klagges et al., 1996; Godenschwege et al., 2004). Additionally, anti-synapsin antibody staining of synaptic terminals at larval muscles was gone in synapsin mutants, while wildtype larvae showed synapsin-immunoreactivity (Michels et al., 2005). The anti-synapsin staining pattern reported in this study is identical to previous reports (Godenschwege et al., 2004; Michels et al., 2005).

\section{$T \beta H$}

In immunoblots of protein extracts from Drosophila heads and bodies a single band corresponding to the 
76-kDa protein was observed using the anti-T $\beta H$ antibody (Monastirioti et al., 1996). T $\beta \mathrm{H}$ immunoreactivity was nearly abolished in larval brains of $T \beta H$ mutants (Monastirioti et al., 1996).

\section{Anti-p-tyramine}

The anti-TA antibody was used to characterize tyraminergic neurons in Drosophila and locust (Busch et al., 2009; Kononenko et al., 2009). The specificity of the antibody was tested by competition experiments in equilibrium dialysis (Geffard et al., 1984). The crossreactivity ratio at half displacement of the labeled ligand and different unlabeled catecholamine conjugates (including TA conjugate) was determined. The best displacement was observed with the TA conjugate, while the OA conjugate was 42 times less immunoreactive (Geffard et al., 1984).

\section{Anti-conjugated octopamine}

The specificity of the anti-OA antibody was determined by competition experiments in an enzyme-linked immunosorbent assay (ELISA) test. The antibody was raised against an octopamine-glutaraldehyde-bovine serum albumin conjugate. Therefore, the crossreactivity ratio (OAG-BSA concentration/concentration of unconjugated or conjugated catecholamine at half time) for OA-G-BSA was the highest. The crossreactivity to TA-G-BSA, other amine-conjugates, and unbound octopamine was drastically reduced (Mons and Geffard, 1987).

\section{Microscopy and figure production}

CNS preparations and filets were scanned using a confocal light scanning microscope (LeicaTCS SP5, Leica Microsystems, Wetzlar, Germany). The images scanned with a step size of $1 \mu \mathrm{m}$ or $0.8 \mu \mathrm{m}$ thickness were projected and analyzed with the software program Image ( $\mathrm{NIH}$, Bethesda, MD). Contrast, brightness, and coloring were adjusted with Photoshop (Adobe Systems, San Jose, CA). Amira 5.3. (Visage Imaging, Berlin, Germany) was used to produce frontal views of the single-cell projections, for the dorsal view on the VNC in Fig. 1C, and for the higher magnifications of the efferents in Fig. 1D-G.

\section{Behavioral experiments}

For the locomotion assay, single larvae of a given genotype were recorded with a standard camera (Casio Exilim series) for 1 minute on a Petri dish $85 \mathrm{~mm}$ in diameter filled with agarose. ImageJ plugin "Grid" was used to divide the plate optically into squares measuring 400 pixels. The number of squares per minute crossed by the larva was used as a function of locomotion. Single traces were obtained by Image plugin "Manual tracking."

\section{Statistical methods}

For the comparison between genotypes, a Wilcoxon Rank Sum test was used. To compare single ge notypes against chance level we used a Wilcoxon signed ranked test. All statistical analyses and visualizations were done with R v. 2.8.0 (R Development Core Team, 2011). Figure alignments were done with Adobe Photoshop. Data are presented as boxplots, including all values of a given genotype, $50 \%$ of the values being located within the box. The median performance index or preference index, respectively, was indicated as a bold line within the boxplot. Significance levels between genotypes shown in the figures refer to the $P$-values obtained in the statistical tests.

\section{RESULTS}

\section{Octopaminergic/tyraminergic neurons of the larval ventral nerve cord}

To reliably visualize OA/TA neurons in the VNC, we used the Tdc2-Gal4 line crossed to UAS-Cameleon2.1 (Diegelmann et al., 2002; Cole et al., 2005). Tyrosine decarboxylase is the enzyme involved in the first step of $\mathrm{OA}$ synthesis, i.e., the conversion of tyrosine into tyramine. Therefore, all Gal4-expressing neurons should be tyraminergic and most of them should also be octopaminergic. To analyze the cellular anatomy of the OA/TA system in the larval CNS, we used anti-FasciclinII (FasII)/anti-Cholineacetyltransferase (ChAT) background staining (Fig. 1), which labeled axonal tracts and neuropils, respectively.

The VNC in Drosophila, like in other arthropods, is composed of three thoracic neuromeres (t1-t3), eight abdominal neuromeres (a1-a8), and a small terminal neuromere at the end of the abdomen (Campos-Ortega, 1997). Each of these 12 neuromeres carried one cell cluster of $T d c 2-$ Gal4-positive neurons (see also Vömel and Wegener, 2008). The cell bodies were located ventromedially (VM) in clusters tVM1 to aVM8, while the terminal neuromere showed a dorsomedially located cluster (aDM9; Fig. 1A). The three thoracic and the first abdominal cluster contained five TDC-positive neurons each (Fig. 1.A,H; Table 2). Three of these cells, which seemed to be VUM neurons, sent their primary neurites dorsally (arrows, Fig. $1 \mathrm{H})$, while one cell per side, called here ventral paired median (VPM) neuron (termed vumTDC2 and pmTDC2 neurons in Vömel and Wegener, 2008), projected anteriorly (asterisk and arrow, Fig. 11). From neuromere a2 toward the posterior, in each neuromere only three VUM neurons were observed (Fig. 1A; Table 2). The neuromere a 8 may contain two VUM neurons, while the terminal neuromere a9 comprised two DUM neurons (Fig. 1A; Table 2; dmTDC2 neurons in Vömel and Wegener, 2008). Taken together, we counted $\approx 42$ potentially OA/TA-producing 

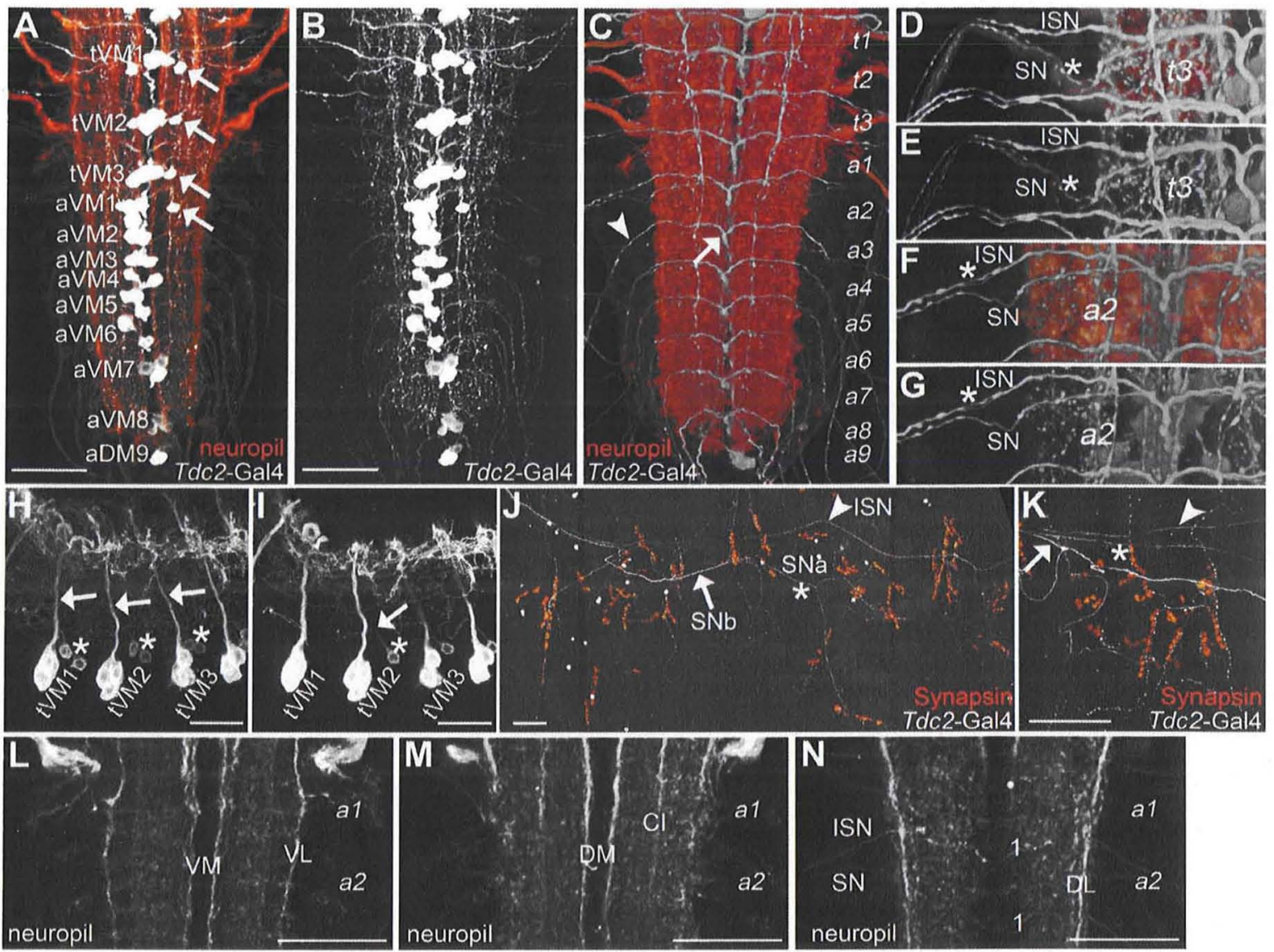

Figure 1. Innervation pattern of Tdc2-Gal4 in the VNC and abdominal muscles. A-I: Tdc2-Gal4 expression in the ventral nerve cord (VNC) of the Drosophila larva. White: Tdc2-Gal4; UAS-Cameleon2.1, anti-GFP; orange: anti-ChAT/anti-FasIl. A,B: Horizontal projections of a larval VNC showing Tdc2-Gal4-positive cell clusters in the thoracic and abdominal neuromeres. tVM1-aVM8 clusters contain VUM neurons, while aDM9 consists of DUM cells. The thoracic neuromeres and the first abdominal neuromere (a1) additionally express Gal4 in one VPM neuron per side (arrows). C: Dorsal view of the VNC showing the laterally bifurcating VUM neurons of VVM1 to aVM8 (arrow) and their neurites projecting via the peripheral nerve to the muscles (arrowhead). D-G: Higher magnification of projections in $t 3(D, E)$ and a2 (F,G), respectively, and their peripheral nerves. Two main nerve trunks, the intersegmental (ISN) and segmental nerve (SN), join to form the peripheral nerve of $\mathrm{t} 1$ to a8. Two of the three VUM neurons in $\mathrm{t} 3$ project via the $\mathrm{SN}$, while in a2 two VUM efferents arise via the ISN (ISN; asterisks). $\mathrm{H}, \mathrm{I}$ : Lateral view of the thoracic and first abdominal neuromere (dorsal up). $\mathrm{H}$ : The primary neurites of the three VUM cells per cluster are randomly twisted while projecting dorsally (arrows). I: Projection of a subset of sections of $\mathrm{t} 1-\mathrm{a} 1$ seen in F, showing the anteriorly arborizing primary neurite (arrow) of the tVPM2 neuron (cell body marked by asterisk). J-K: Tdc2-Gal4 expression at the abdominal body wall muscles. White: Tdc2-Gal4; UAS-Cameleon2.1, anti-GFP; orange: anti-synapsin, type I bouton marker. Abdominal body wall muscles are innervated by one Gal4-positive axon in the ISN (arrowhead), one in the SNb (arrow), and another one in the SNa (asterisk) branch. L-N: Horizontal projections of ventral (L), medial (M), and dorsal (N) layers of the neuromeres a1 and a2. Nomenclature after Landgraf et al. (2003): VM, ventral median; VL, ventral lateral; DM, dorsal median; Cl, central intermediate; DL, dorsal lateral fascicle; 1 , transverse projection TP1. Scale bars $=\mathrm{A}, \mathrm{B}, \mathrm{J}, \mathrm{K} 50 \mu \mathrm{m}, \mathrm{H}, \mathrm{I}, \mathrm{L}-\mathrm{N} 25 \mu \mathrm{m}$.

cells in the whole VNC: five in each thoracic and the first abdominal neuromere ( $\mathrm{t} 1-\mathrm{t} 3$, a 1$)$, three per cluster in neuromeres a2 to a7, and two per cluster in the last two abdominal neuromeres a8 and a9 (Table 2).

The VUM neurons bifurcated in the dorsalmost part of the VNC (arrow, Fig. 1C) and projected laterally to extend to the peripheral nerves (arrowhead, Fig. 1C). In segments $\mathrm{t} 1-\mathrm{t} 3$ and $\mathrm{a} 1-\mathrm{a} 7$, the peripheral nerve was formed by the fusion of two main nerve trunks, the intersegmental nerve (ISN) and the segmental nerve (SN), which both included motor and modulatory neurons (Thomas et al., 1984; Monastirioti et al., 1995; Landgraf et al., 1997). Similar to reports from embryos, it seemed that one VUM neuron in the abdominal neuromeres a 1 to a7 projected along the SN, while the other two neurons perhaps used the posterior ISN to enter the peripheral nerve (Fig. IF,G) 
TABLE 2.

Cell Numbers of Tdc2-Gal4 and/or T $\beta$ H-Expressing Neurons

\begin{tabular}{|c|c|c|c|c|c|c|c|c|c|c|c|c|}
\hline \multirow[b]{3}{*}{ Cell cluster } & \multicolumn{9}{|c|}{ Tdc2-Gal4; UAS-Cameleon2. 1} & \multirow{2}{*}{\multicolumn{3}{|c|}{$\begin{array}{c}\begin{array}{c}T d c 2-G a l 4 / \text { tshGal80; } \\
\text { UAS-Cameleon2.1 }\end{array} \\
\text { aGFP } \\
\end{array}$}} \\
\hline & \multicolumn{3}{|c|}{ aGFP } & \multicolumn{3}{|c|}{ aTßH } & \multicolumn{3}{|c|}{ aGFP/ aT $\beta H$} & & & \\
\hline & & SEM & $n$ & & SEM & $n$ & & SEM & $n$ & & SEM & $n$ \\
\hline tVM1 & 5.18 & 0.12 & 11 & 5.09 & 0.09 & 11 & 5.09 & 0.09 & 11 & 2.22 & 0.15 & 9 \\
\hline tVM2 & 5.36 & 0.28 & 11 & 5.09 & 0.09 & 11 & 5.09 & 0.09 & 11 & 0.38 & 0.26 & 8 \\
\hline tVM3 & 5.09 & 0.09 & 11 & 4.82 & 0.18 & 11 & 4.82 & 0.18 & 11 & 0.25 & 0.16 & 8 \\
\hline aVM1 & 4.91 & 0.09 & 11 & 4.82 & 0.18 & 11 & 4.91 & 0.09 & 11 & 0.00 & 0.00 & 7 \\
\hline aVM2 & 3.00 & 0.00 & 11 & 3.00 & 0.00 & 11 & 3.00 & 0.00 & 11 & 0.00 & 0.00 & 7 \\
\hline aVM3 & 3.00 & 0.00 & 11 & 3.00 & 0.00 & 11 & 3.00 & 0.00 & 11 & 0.00 & 0.00 & 7 \\
\hline aVM4 & 3.00 & 0.00 & 11 & 3.00 & 0.00 & 11 & 3.00 & 0.00 & 11 & 0.00 & 0.00 & 7 \\
\hline aVM5 & 3.00 & 0.00 & 11 & 3.00 & 0.00 & 11 & 3.00 & 0.00 & 11 & 0.00 & 0.00 & 7 \\
\hline aVM6 & 3.00 & 0.00 & 11 & 3.00 & 0.00 & 11 & 3.00 & 0.00 & 11 & 0.00 & 0.00 & 7 \\
\hline aVM7 & 3.00 & 0.00 & 10 & 3.00 & 0.00 & 10 & 3.00 & 0.00 & 10 & 0.00 & 0.00 & 7 \\
\hline aVM8 & 2.30 & 0.15 & 10 & 2.00 & 0.00 & 10 & 2.00 & 0.00 & 10 & 1.43 & 0.30 & 7 \\
\hline aDM9 & 2.50 & 0.17 & 10 & 2.00 & 0.26 & 10 & 2.00 & 0.26 & 10 & 1.14 & 0.34 & 7 \\
\hline VGlat $\left({ }^{\star}\right)$ & 0.00 & 0.00 & 11 & 2.91 & 0.09 & 11. & 0.00 & 0.00 & 11 & 0.00 & 0.00 & 7 \\
\hline vnc & 43.80 & 0.66 & 10 & 47.70 & 0.50 & 10 & 42.00 & 0.45 & 10 & 5.14 & 0.46 & 7 \\
\hline
\end{tabular}

*Per side. t, thoracic; a, abdominal; VM, ventral median; DM, dorsal median; VG, ventral ganglion; lat, lateral; vnc, ventral nerve cord.

(Sink and Whitington, 1991). For the thoracic neuromeres, we mostly observed two axons in the SN branch (Fig. 1D,E), but also cases in which two VUM neurons of the thoracic clusters projected into the ISN (data not shown).

To understand whether all Tdc2-Gal4-positive cells are octopaminergic we performed double labeling with a T $\beta \mathrm{H}$ antibody (Monastirioti et al., 1996) and anti-GFP in Tdc2-Gal4; UAS-Cameleon2.1 larvae. TBH is the enzyme necessary for $\mathrm{OA}$ synthesis from its precursor TA and should therefore be expressed in every octopaminergic cell. All Gal4-expressing cells were also labeled by the $\mathrm{T} \beta \mathrm{H}$ antibody and are therefore both octopaminergic and tyraminergic (Fig. 2A-C; Table 2). Interestingly, Tdc2-Gal4 did not include about three $\mathrm{T} \beta \mathrm{H}$-positive cells per side whose cell bodies were located laterally in neuromeres a2 to a4 (asterisks in the insert of Fig. 2A; Table 2). To independently validate this result, we performed additional experiments by double labeling Tdc2-Gal4; UAS-Cameleon2.1 larvae with either anti-OA and anti-GFP or anti-TA and antiGFP, thereby testing whether the Gal4-positive cells were OA- or TA-positive (Fig. 2D-I). As reported before, the $\mathrm{OA}$ and $\mathrm{TA}$ antibodies showed a high interindividual variability in their staining pattern (Busch et al., 2009). Consequently, we describe here the maximum of colabeled neurons observed in each cluster. All Gal4expressing neurons seemed to be OA- and TA-immunoreactive, while two additional cells in the first thoracic neuromere might be TA-positive only (data not shown). Therefore, the Tdc2-Gal4 driver line specifically labeled nearly all $\mathrm{OA}$ and TA cells in the thoracic and abdominal neuromeres of Drosophila larvae and could ideally be used to analyze the behavioral role and single-cell anatomy of OA/TA neurons by various kinds of genetic intervention.

\section{Octopaminergic/tyraminergic innervation of larval abdominal muscles}

After analyzing the neuronal assembly of the OA/TA system in the larval VNC, we followed the efferent processes of its neurons along the peripheral nerves as well as their neuromuscular innervation patterns. In general, the muscle patterns and their innervation were highly conserved along the abdominal neuromeres a2 to a7, while a1, a8, a9, and the thoracic neuromeres showed different patterns (Bate, 1993; Gramates and Budnik, 1999). Therefore, we focused here on the muscle innervation of OA/TA cells in a2 to a7. When reaching the body wall muscles, the peripheral nerve split into five branches termed ISN, SNa, SNb, SNc, and SNd. It was shown that the efferent axons reaching the muscles through the ISN branch innervated the dorsal and lateral muscles, while neurites extending through the four $\mathrm{SN}$ branches ( $\mathrm{SNa}$ $\mathrm{SNd}$ ) terminated on lateral and ventral muscles (Bate, 1993; Landgraf et al., 1997; Hoang and Chiba, 2001). To describe the OA/TA innervation pattern on the abdominal muscles we labeled Tdc2-Gal4; UAS-Cameleon2.1 larvae with anti-GFP and anti-synapsin. Synapsin is a presynaptic protein located in type I boutons of each muscle (Godenschwege et al., 2004). We were able to observe one Gal4-positive axon in the ISN, one in the SNb and SNd, and another one in the SNa branch (Fig. 1J,K). As two of the three VUM efferents left the abdominal ganglion via the ISN route (VUMisn; Fig. 1F,G), one efferent neurite 

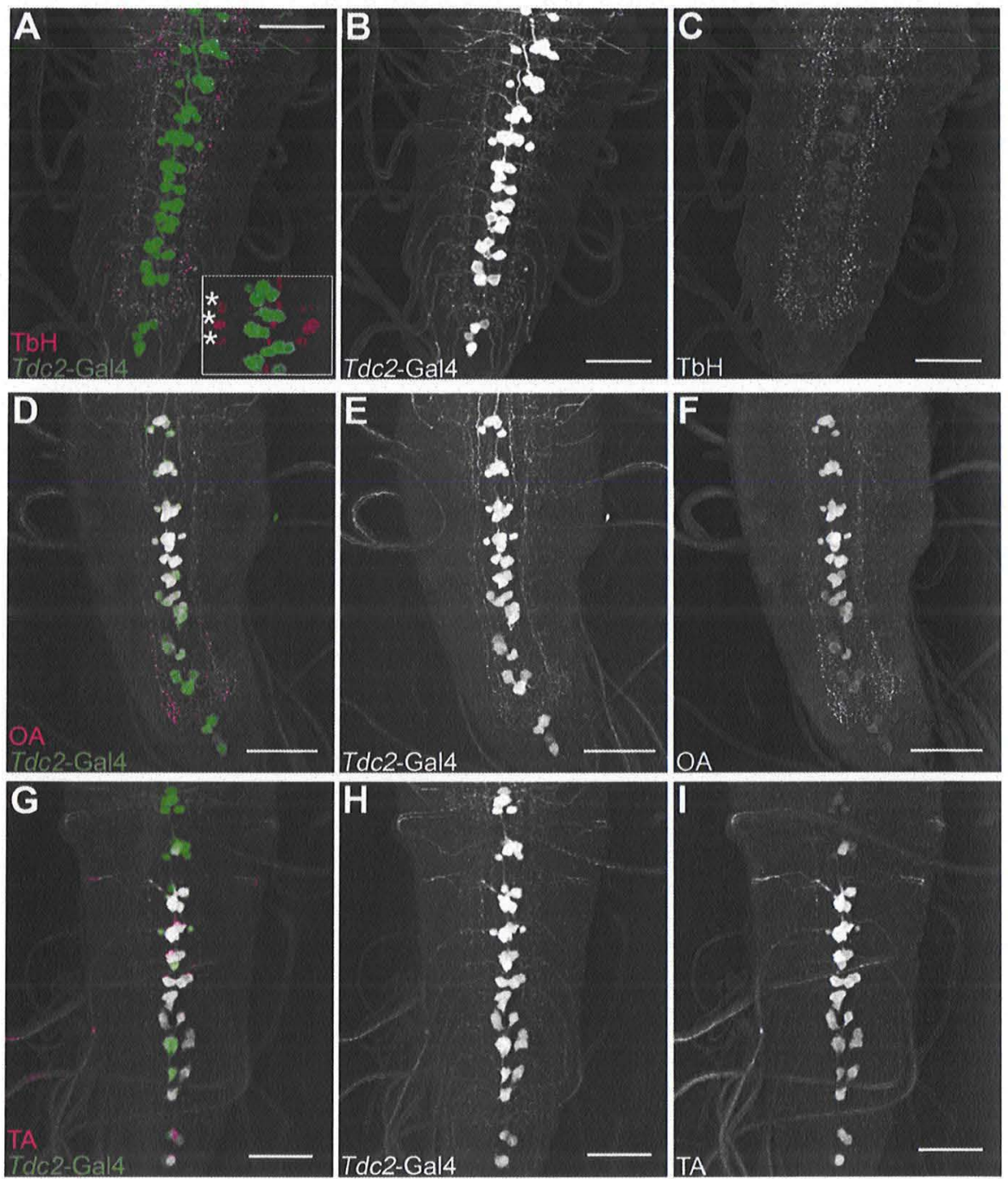

Figure 2. T $\beta \mathrm{H}$-, octopamine-, and tyramine-immunoreactivity in the larval VNC. A,D,G: Tdc2-Gal4 expression in combination with T $\beta \mathrm{H}$ (tyramine $\beta$ hydroxylase)-, OA (octopamine)-, and TA (tyramine)-immunoreactivity, respectively. Green: Tdc2-Gal4; UAS-Cameleon2.1, antiGFPch; magenta: (A) anti-TBH, (D) anti-OA, (G) anti-TA. The second (B,E,H) and third columns (C,F,I) represent the Tdc2-Gal4 expression and T $\beta H / O A / T A$ staining, respectively. A-C: All Tdc2-positive neurons of the larval VNC are also labeled by the T $\beta H$ antibody. Three cell bodies per side in abdominal neuromeres a2-a4 were only TBH-immunoreactive (insert in A, asterisks). D-F: All Tdc2-positive neurons of the larval VNC are also labeled by the OA antibody. The OA staining was variable between specimens. G-I: Almost all Tdc2-positive neurons of the larval VNC are also labeled by the TA antibody. Scale bars $=50 \mu \mathrm{m}$.

innervated the muscles extending through the SNb and $\mathrm{SNd}$ branches (arrow, Fig. 1J,K) while the other neurite used the ISN branch (arrowhead, Fig. 1J,K; for embryo: Landgraf et al., 1997). The neurite of the VUM cell leaving the VNC through the SN (VUMsn) reached the muscles via the $\mathrm{SNa}$ branch. As shown for OA staining, in none of our preparations did we observe an innervation of muscle 6 (VL3) and muscle 7 (VL4), which are devoid of type II boutons (Monastirioti et al., 1995; Koon et al., 2011). For example, when following the peripheral nerve of segment a4, it seemed that all muscles showing synapsin staining (except for muscles 6 [VL3] and 7 [VL4]) are also targets of the Tdc2-Gal4-positive neurons. Therefore, we concluded that one VUMisn neuron projects via the ISN branch onto dorsal muscles (1 [DA 1], 2 [DA2], 3 [DA3], 4 [LL1], 9 [DO1], 10 [DO2], 11 [DO3], 18 [DT1], 19 [DO4], and 20 [DO5]), while the other VUMisn cell branches via SNb and SNd onto ventral muscles (12 [VL1], 13 [VL2], 14 [VO1], 15 [VO4], 16 [VO5], 17 [VO6], 28 [VO3], and 30 [VO2]). The VUMsn neuron innervated lateral muscles (5 [LO1], 8 [SBM], 21 [LT1], 22 [LT2], 23 [LT3], and 24 [LT4]) via the SNa branch (see also Hoang and Chiba, 

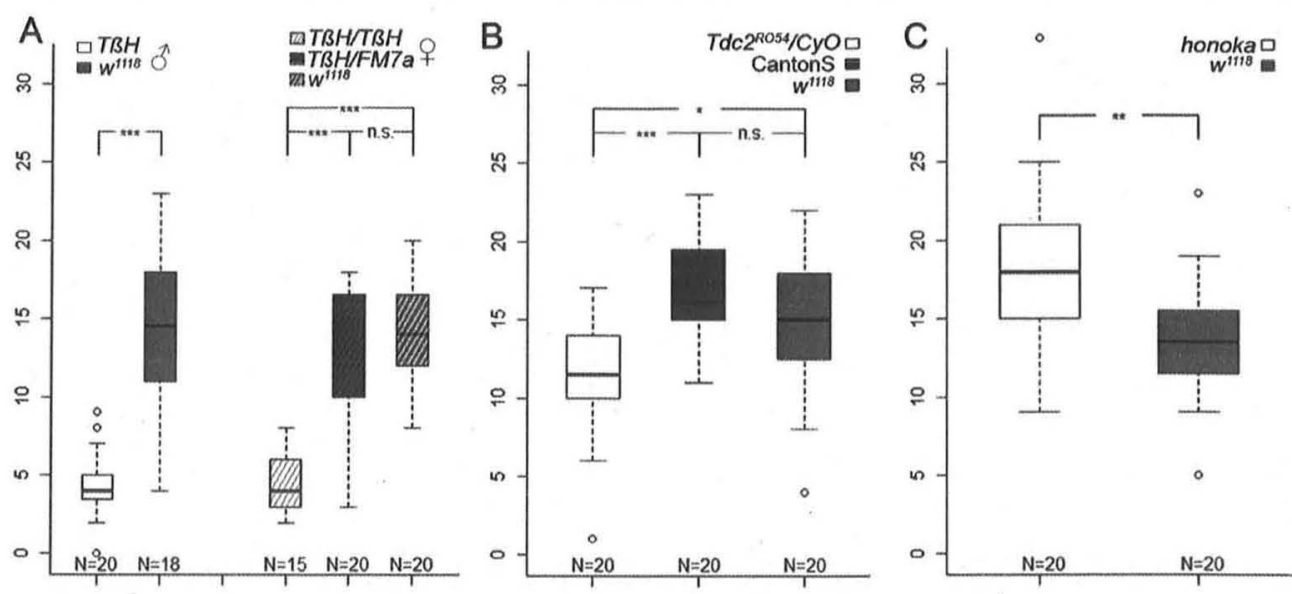

Figure 3. Larval locomotion is antagonistically modulated by OA and TA. A: Hemizygous $T \beta H$ male larvae were significantly reduced in locomotor activity compared to $w^{1118}$ males $\left(P=1.087 \times 10^{-6}\right)$. Locomotion of heterozygous $T \beta H$ females was indistinguishable from that of $w^{1118}$ female controls $(P=0.3141)$. In contrast, homozygous $T \beta H$ female larvae crawled much shorter distances per minute compared to $w^{1 / 18}$ larvae $\left(P=6.395 \times 10^{-7}\right)$ and heterozygous $T \beta H$ larvae $\left(5.457 \times 10^{-6}\right)$. B: $T d c 2^{R O 54} / C y O$ larvae with reduced levels of both $\mathrm{OA}$ and TA showed significantly reduced locomotor activity compared to CantonS $\left(P=3.075 \times 10^{-5}\right)$ and $w^{1118}$ larvae $(P=$ 0.0120 ). C: honoka larvae with a reduced tyramine receptor level were hyperactive and traveled significantly faster than $w^{1118}$ control larvae $(P=0.0047) .{ }^{*}<0.5,{ }^{* *}<0.01,{ }^{* * *}<0.001$, n.s. $>0.05$, asterisks indicate significance levels between genotypes; $N=$ sample size.

2001). It might be that the VUMsn also projects to the SNc branch to innervate muscles 26 (VA1), 27 (VA2), and 29 (VA3).

\section{Larval locomotion is antagonistically modulated by $\mathrm{OA}$ and TA}

Following the approach of Saraswati et al. (2004), we revisited the role of $O A$ and $T A$ in larval locomotion. To this end, we did an integrative behavioral analysis of three different mutant strains, lacking either $\mathrm{OA}(T \beta H)$, both $\mathrm{OA}$ and TA $\left(T d c^{R O 54}\right)$, or having a reduced TA receptor level (honoka).

Larval locomotion can be separated into different components including distance, speed, and directional changes. To robustly quantify locomotion we focused on the distance that single larva traveled within 1 minute on an agarose plate that was virtually divided into smaller squares (see Materials and Methods). Recording was made by counting how many squares per minute the larvae crossed on their path.

Similar to Saraswati et al. (2004), TRH mutant larvae exhibiting reduced OA and elevated TA levels (Monastirioti et al., 1996) showed severe impairments in locomotion compared to their appropriate controls (Fig. 3A). In detail, both hemizygous male and homozygous female larvae were strongly reduced compared to $w^{1118}$ males and females $\left(P=1.087 \times 10^{-6}\right.$ for male comparison; 6.395 $\times 10^{-7}$ for female comparison), respectively. In contrast, heterozygous female larvae were indistinguishable from control larvae $(P=0.3141)$. Furthermore, we wanted to address whether TA, the precursor of $O A$, is also involved in the regulation of locomotion. First we used $T d c 2^{R O 54}$ larvae, deficient for tyrosine decarboxylase and therefore lacking both TA and OA (Fig. 3B). Tdc2 ${ }^{R O 54}$ larvae balanced over $\mathrm{CyO}$ were significantly reduced in locomotion compared to Cantons $\left(P=3.075 \times 10^{-5}\right)$ and $w^{1118}(P$ $=0.0120)$ control larvae, which performed equally $(P=$ $0.1274)$. Locomotion tended to be even further reduced in homozygous $T d c 2^{R O 54}$ larvae (data not shown). Finally, we analyzed if larval locomotion is affected by reduced levels of the TA receptor. In our assay, honoka larvae performed significantly better than the controls, as reflected by enhanced distance scores within 1 minute (Fig. 3C; $P$ $=0.0047$ ). This phenotype is in line with results published by Kutsukake et al. (2000), who reported that adult flies with a reduced number of TA receptors show slightly increased locomotor activity compared to wildtype flies. Taken together, our data demonstrate that OA and TA are involved in larval locomotion and that the reduction of TA receptors triggers hyperactivity, similar to adult flies.

To confirm and extend our findings we interfered with the OA/TA system by using the Gal4/UAS technology (Brand and Perrimon, 1993). In detail, we used the Tdc2Gal4 line to drive expression of transgenes specifically in OA/TA neurons, to either ablate them (UAS-Hid,Rpr; Grether et al., 1995; Hay et al., 1995) or to block synaptic transmission (UAS-Kir2.1; Baines et al., 2001). In the same assay as used above, Tdc2-Gal4/UAS-Hid,Rpr 

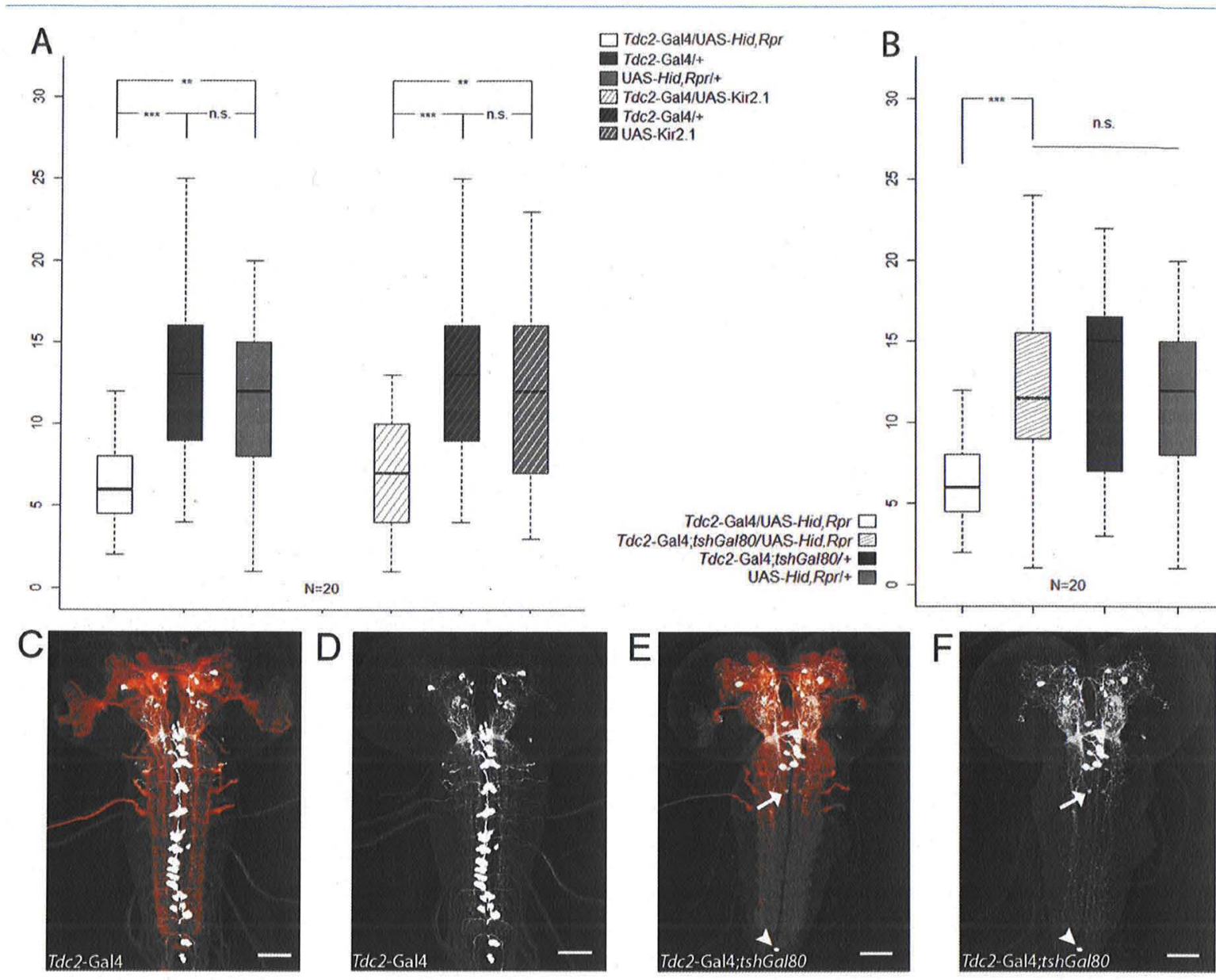

Figure 4. Octopaminergic/tyraminergic neurons are involved in larval locomotion. A: Both the expression of the cell ablation genes Hid,Rpr and of the inwardly rectifying potassium channel Kir2.1 in Tdc2-positive cells led to strongly reduced distances traveled within 1 minute compared to Gal4/+ and UAS/+ control larvae. B: The combined expression of Tdc2-Gal4 and tshGal80 inhibited the Hid,Rprinduced locomotion phenotype. These larvae performed significantly better than Tdc2-Gal4/UAS-Hid,Rpr but indistinguishable from Tdc2Gal4;tshGal80/+ $(P=0.6156)$ and UAS-Hid,Rpr/ $+(P=0.7144)$ larvae. C,D: Tdc2-Gal4 expression in the larval CNS. White: Tdc2-Gal4; UAS-Cameleon2.1, anti-GFP; orange: anti-ChAT/anti-Fasll. E,F: Tdc2-Gal4;tshGal80 expression in the larval CNS. White: Tdc2-Gal4; tshGal80/ UAS-Cameleon2.1, anti-GFP; orange: anti-ChAT/anti-Fasll. No detectable staining of the octopaminergic/tyraminergic cells in the VNC is visible except for the VPM neurons in the $\mathrm{t} 1$ neuromere (arrow) and one cell in the aDM9 cluster (arrowhead). ${ }^{*}<0.5$, ${ }^{* *}<0.01,{ }^{* * *}<0.001$, n.s. $>0.05$, asterisks indicate significance levels between genotypes; $N=$ sample size. Scale bars $=50 \mu \mathrm{m}$.

larvae showed strongly reduced forward locomotion. Compared to $T d c 2-G a l 4 /+\left(P=6.3 \times 10^{-5}\right)$ and UASHid,Rpr $/+(P=0.0015)$ larvae, experimental larvae showed a nearly $50 \%$ reduction in terms of squares crossed per minute (Fig. 4A). In this experiment, control larvae elicited a characteristic searching behavior to explore the arena. In contrast, ablation of OA/TA cells led to altered locomotor patterns, as these larvae showed partially a circling behavior resulting in smaller distances traveled per minute (data not shown). Next, we analyzed whether Tdc2-Gal4/UAS-Kir2.1 larvae were also affected in locomotion. In these larvae, electrical silencing of synaptic transmission in OA/TA neurons may not destroy the hardwiring of the network, as is the case in the genetically ablated larvae. Similar to previous results, Tdc2-Gal4/ UAS-Kir2.1 larvae also showed about a 50\% reduction in squares crossed per minute compared to their appropriate controls (Fig. 4A; $P=0.0002$ compared to $T d c 2$ Gal4/+ and $P=0.0045$ compared to UAS-Kir2.1/+). Again, as described above, single exemplary traces revealed aberrant locomotor phenotypes, as experimental larvae showed partially a circling behavior, whereas control larvae generally tended to reach the edges of the Petri dish within 1 minute (data not shown).

Taken together, OA/TA neurons seem to play a major role in larval locomotion, as genetic ablation and 

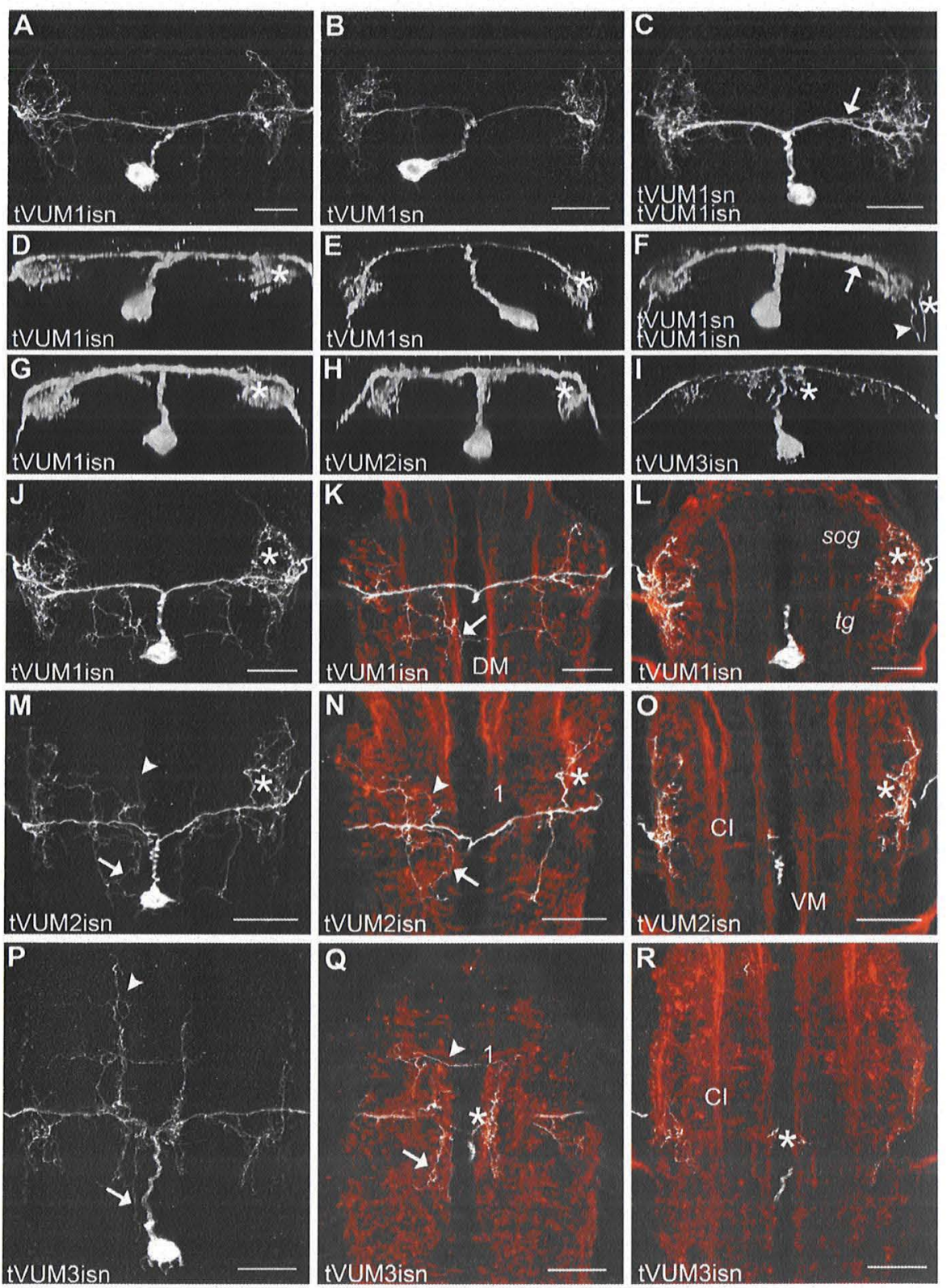

Figure 5. Anatomy of single VUM neurons of the larval thoracic ganglion. A-R: Projection pattern of single octopaminergic/tyraminergic VUM neurons of the thoracic neuromeres. White: Tdc2-Gal4; UAS-mCD8::GFP, anti-GFP; orange: anti-ChAT/anti-Fasll. A-G,J-L: The main neuropil innervation patterns of the efferent VUM neurons in the thoracic neuromere $t 1$ and their projections through the intersegmental nerve (ISN) or segmental nerve (SN) seems to be identical. Ramifications are mostly found in the lateral neuropil of $\mathrm{t} 1$ and the posterior SOG (asterisks). C: Horizontal projection of the anterior thoracic neuromeres and the SOG. Two IVUM1 neurons are stained in the same VNC. The cells differ only with respect to the axonal projection from the lateral dorsomedial neuropil (arrow) to the peripheral nerve. F: Frontal view of the cell shown in C. The axon projecting in the SN (arrowhead) runs ventrally from the lateral dorsomedial neuropil, while the efferent from the VUMisn cell (asterisk) stays at the dorsal margin of the neuropil. G,J-L: Frontal (G) and horizontal projection of a tVUM 1isn neuron. J: The whole projection pattern; K: The dorsalmost arborizations of the cell, while L: represents medial and ventral layers. K: Ramifications in the dorsomedial region of neuromere t2 are visible (arrow). L: tVUM 1isn innervates the posterior SOG laterally. H: Frontal view of the IVUM2isn neuron which mainly ramifies in the lateral neuropil (asterisk). M-O: Horizontal projections of the entire cell $(M)$, dorsal $(N)$, and medial to ventral layers $(0)$, respectively. The tVUM2isn neuron ramifies in the lateral neuropil (asterisks). The arrows indicate dorsomedial arborizations innervating the posterior neuromere $\mathrm{t} 3$, while the arrowheads point to anterior projections in the dorsomedial neuropil which were never observed in tVUM1 neurons. I: Frontal view of the tVUM3isn cell. Medial projections (asterisk) are not restricted to the dorsal neuropil unlike in IVUM1 and tVUM2 cells. P-R: Horizontal projections of the entire cell (P), dorsal (Q), and medial layers (R), respectively. Anterior (arrowhead) and posterior (arrow) dorsomedial arborizations in the neighboring neuromeres are visible. R: tVUM3 ramifies around the midline in medial neuropil.regions at the level of the central intermediate fascicle (CI). Scale bars $=25 \mu \mathrm{m}$ 
electrical silencing of these neurons led to similar movement impairments as shown for mutants lacking $O A$ and/ or TA (Kutsukake et al., 2000; Saraswati et al., 2004; Fox et al., 2006; this study).

\section{Octopaminergic/tyraminergic neurons within the ventral nerve cord are necessary for larval locomotion}

In order to restrict the expression pattern of Tdc2-Gal4 to the hemispheres and SOG and thereby separate brain function of OA/TA from its thoracic and abdominal function, we crossed the driver line to tshGal80 (Clyne and Miesenböck, 2008), which was shown to block Gal4expression specifically within the VNC. Expression of UAS-Cameleon2.1 (Diegelmann et al., 2002) driven by Tdc2-Gal4;tshGal80 did not reveal any detectable staining in the VNC except for about two cells in the 11 neuromere and one cell each in the ventral and dorsal cluster in the abdominal neuromeres a8 and a9 (Fig. 4C-F; Table 2). To analyze if OA/TA neurons within the VNC are key players in locomotion, we expressed UAS-Hid,Rpr driven by Tdc2Gal4;tshGal80. Experimental larvae showed normal locomotion compared to the corresponding controls $(P=$ 0.6156 compared to Tdc2-Gal4;tshGal80/+ and $P=$ 0.7144 compared to UAS-Hid,Rpr/+; Fig. 4B). Furthermore Tdc2-Gal4;tshGa/80/UAS-Hid,Rpr showed an intact searching behavior, i.e., normal traces toward the edges of the Petri dish (data not shown). Hence, limiting the expression of the ablation-inducing transgenes Hid and Rpr to OA/TA cells outside of the VNC "rescued" the locomotor effect. Thus, OA/TA-positive cells within the VNC are crucial for modulating forward locomotion in the larva.

\section{Characterization of single octopaminergic/ tyraminergic neurons of the larval ventral nerve cord}

To describe the octopaminergic/tyraminergic cells of the VNC in detail, single neurons were identified with the aid of the flp-out technique (Wong et al., 2002). Specifically, individual $T d c 2-$ Gal4-positive neurons were labeled by anti-GFP and described within a Fasll/ChAT background staining. Anti-Fasll staining allowed a straightforward comparison of these neurons with respect to the nomenclature of Landgraf et al. (2003) for abdominal Fasllpositive tracts (Fig. 1L-N). In this terminology, characteristic longitudinal axonal tracts were named according to their relative position in the dorsoventral ( $D$ dorsal; $C$ central; $\mathrm{V}$ ventral) and mediolateral ( $\mathrm{M}$ median; I intermediate; L lateral) axis of the VNC: The five transverse projections were called TP1 to TP5.

In general we were able to identify three different types of neurons in the larval VNC: VUM, VPM, and DUM neu- rons. The clusters tVM1 to aVM8 contained VUM cells, while VPM cells were restricted to IVM 1-aVM1 and DUM cells were restricted to the terminal segment. Whereas the cell bodies of the VUM and DUM neurons seemed to be similar in size, VPM cells possessed slightly smaller somata (asterisks, Fig. $1 \mathrm{H}, \mathrm{I}$ ). Below we characterize the OA/TA VUM neurons of the larval VNC, followed by the two DUM cells of a9 and the VPM neurons of the neuromeres $\mathrm{t} 1 \mathrm{t} \mathrm{t} 3$ and $\mathrm{a} 1$.

\section{Characteristics of larval VUM neurons}

All VUM neurons sent their primary neurites in a bundle to the dorsal margin of the neuropil where they split in a t-shaped manner (arrow, Fig. 1C) (see also Vömel and Wegener, 2008). The primary neurites of the three VUM neurons within each cluster were randomly twisted while passing from the cell bodies dorsally through the neuropil. After the split, each of the three axons projected laterally and extended into the peripheral nerve either via the transverse projection TP1 ("1" in Fig. 1N), which represents the pISN (Landgraf et al., 2003), or more ventrally into the SN (Fig. 1D-G). Therefore, at least two distinct types of VUM neurons exist that differed in the route their axons followed to enter the nerve and thus also in the muscles they innervated. In fact, it seemed that the three VUM neurons per cluster show nearly the same arborization pattern in the neuropil (Figs. 5, 6, 9) while differing completely in their muscular innervation pattern. As none of our single-cell preparations included the muscle innervations, we could only distinguish between the routes taken by the neurites to enter the peripheral nerve. Hence, we named the cells according to their cluster of origin and their neuropil exit route (e.g., tVUM1isn or tVUM1sn).

\section{VUM neurons of the thoracic neuromeres}

The main innervation region of the TVUM 1 neurons was the lateral edge of the $t 1$ neuromere and the posterior SOG (asterisks, Fig. 5D,E,G,J,L). Interestingly, the cells projecting through ISN and $\mathrm{SN}$ seemed to be similar with respect to their neuropil innervation (Figs. 5A-C,J, 9) but differed in their main projection from the dorsomedial neuropil to the peripheral nerve (arrows, Fig. 5C,F; 5F arrowhead shows SN, asterisk ISN projection). In between specimens variations between the numbers and length of ramifications existed, while the characteristic projections remained equal (Fig. 5A,J). In most preparations, arborizations from the primary neurite extended into the dorsal posterior neuropil, innervating the anterior part of the $\mathrm{t} 2$ neuromere (arrow, Fig. 5K). These mostly dorsomedial bifurcations were restricted to the dorsalmost part of the neuropil and could also be observed in VUM cells of the $\mathrm{t} 2$ and $\mathrm{t} 3$ neuromeres (arrows, Figs. 

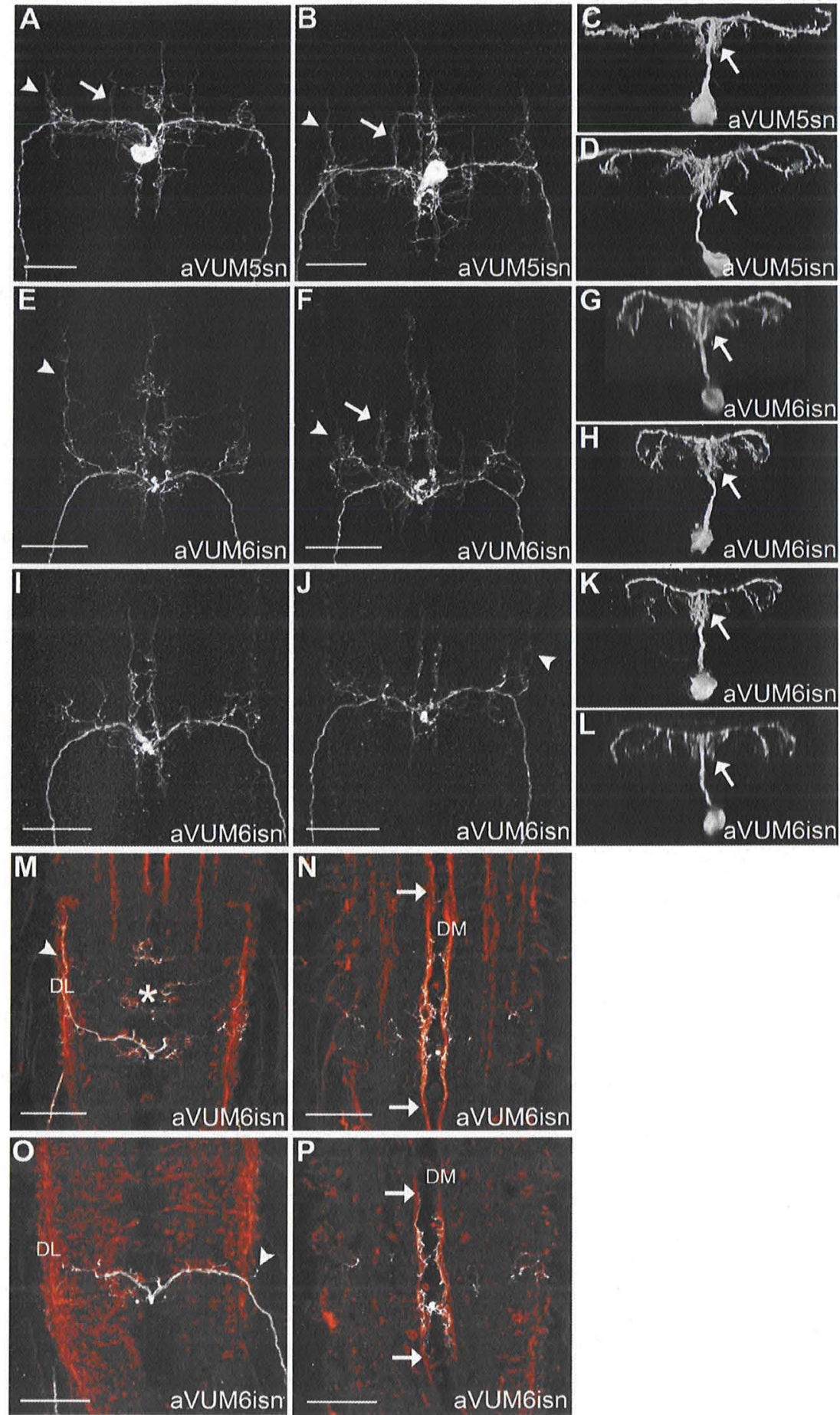

Figure 6. Anatomy of single VUM neurons of the larval abdominal ganglion. A-P: Projection pattern of single octopaminergic/tyraminergic VUM neurons in the abdominal neuromeres a5 and a6. White: Tdc2-Gal4; UAS-mCD8::GFP, anti-GFP; orange: anti-ChAT/anti-FasIl. $A, B, E, F, I, J$ : Horizontal projection pattern of the entire neuron. Apart from the main projections in the dorsomedial neuropil, ramifications are visible at the lateral margin of the neuropil (arrowhead) and dorsal to the central intermediate fascicle (arrow). A,B: The VUM neurons of each cluster seem to differ only with respect to their efferents. E,F,I,J: As seen in four different specimens, aVUM6isn cells vary in their length and number of arborizations, while the main projection remain the same. C,D,G,H,K,L: Frontal view of the entire VUM neurons. The median arborizations extend to the more ventral neuropil (arrows), but remain dorsal to the ventral median fascicle. M-P: Horizontal projections of a few sections of the dorsalmost neuropil including the dorsal lateral fascicle $(D L ; M, O)$ and of the dorsal neuropil including the dorsal median fascicle (DM; N,P), respectively. (M) aVUM neurons show arborizations in the mediodorsal neuropil (asterisk) and along the DL (arrowhead). N: Ramifications along the DM seem to reach anterior neuromeres as well as the posterior neuromere a7 (arrows). O: Small branches near the DL are visible (arrowhead). P: Arborizations innervate anterior the neuromeres a5 and a4 and seem to reach the adjacent posterior neuromere a7 (arrows). Scale bars $=25 \mu \mathrm{m}$. 
$5 \mathrm{M}, \mathrm{N}, \mathrm{P}, \mathrm{Q}, 9)$, although also anterior projections occurred in the VUM neurons of $\mathrm{t} 2$ and $\mathrm{t} 3$ (arrowheads, Fig. $5 M, N, P, Q)$. The lateral arborizations of tVUM2 and tVUM3 neurons covered an area from the dorsomedial to the dorsolateral neuropil, i.e., dorsal to the central lateral fascicles in its own as well as in the anterior neuromere (asterisks, Fig. 5H,M-O). The tVUM3 neurons also ramified in the neuropil around the dorsal median fascicle in the $\mathrm{t} 3$ neuromere (asterisks, Figs. 5I,Q,R, 9).

\section{VUM neurons of the abdominal neuromeres a1 to a7}

For the VUM neurons of abdominal neuromeres a 1 to a7, the main arborization pattern seemed to be essentially identical, as demonstrated in Figure 6A-L. Nevertheless, variations in the number and length of ramifications were present between different specimens. Apart from the characteristic efferent projections of all VNC VUM neurons, cells of the neuromeres a 1 to a7 seemed to arborize along and dorsal to the dorsal median (DM) fascicle (arrows, Fig. $6 \mathrm{~N}, \mathrm{P}$ ) and laterally along the dorsal lateral (DL) fascicle (arrowheads, Figs. 6A,B,E,F,J,M, 9). These innervations were not restricted to the neuromere of origin but also invaded the next anterior neuromere (Fig. 6). In the dorsomedial neuropil the neurons sent arborizations at least into two (mostly three) anterior neuromeres and always into the adjacent posterior neuromere (Fig. 6N,P); in all these neuromeres they seemed to cross the midline in both posterior and anterior commissures. Each neuron also ramified in the region ventral to the dorsal median (DM) fascicle, but dorsal to the dorsally ventral median (VMd) fascicle of its own segment (arrows; Figs. 6C,D,G,H,K,L, 9). Additionally, we observed in most of our single-cell preparations arborizations dorsal to the central intermediate $(\mathrm{Cl})$ fascicles both in the neuromere of origin and in one neuromere anterior (arrow, Fig. $6 \mathrm{~A}, \mathrm{~B}, \mathrm{~F})$. Several small ramifications projected from these intermediate axons to the midline.

\section{VUM and DUM neurons of the last abdominal neuromeres}

The OA/TA neurons of the neuromeres $a 8$ and $a 9$ innervated nearly all parts of the dorsal neuropil of their own neuromere (Fig. 7) but also reached anterior neuromeres, again mainly in the dorsomedial parts of the neuropil (arrows, Fig. 7). Likewise, longitudinal arborizations reaching anterior neuromeres were observed dorsal to the $\mathrm{Cl}$ fascicles and around the DM fascicle (arrowheads, Fig. 7).

The two OA/TA neurons of neuromere a9 had dorsally located cell bodies (aDUM9 neurons). For these neurons we obtained only one adequate preparation (Fig. $7 \mathrm{H}-\mathrm{J}$ ) allowing a preliminary description. In this preparation the
aDUM9 neuron arborized mostly in the dorsal part of the terminal neuromere a9 (Fig. 7l), its neurites also excessively branched in the dorsal and medial neuropil of the neuromere a8 and even reached the posterior part of a7 (Fig. 7I).

\section{VPM neurons}

The cell bodies of the VPM neurons resided lateral to the midline in the ventral cortex. Their primary neurite projected anteriorly and crossed the midline in the neuromere of origin, potentially touching the neurite of the contralateral sister neuron. VPM neurons established arborizations mainly in the contralateral neuropil.

Given that in none of the $500 \mathrm{flp}$-out stainings the tVPM 1 cell type was labeled alone, we cannot accurately describe its anatomy. The tVPM2 cell innervated the medial contralateral neuromere $\mathrm{t} 1$ and the SOG (Fig. 8AD). After crossing the midline, the primary neurite ran toward the lateromedial area of the thoracic ganglion where it split into two processes (arrowhead, Fig. 8A,D). Ramifications projected into the ventromedial SOG (Fig. 8D). A secondary neurite bifurcated in the dorsomedial neuromere $\mathrm{t} 1$ and innervated the mediodorsal SOG and tritocerebrum (Fig. 8B).

The tVPM3 cell type projected additionally to the lateral edge of the thoracic ganglion (arrowhead, Fig. 8E,G). After reaching the contralateral side of the neuromere $\mathrm{t} 3$, the primary neurite bifurcated. One process ran anteriorly and reached the SOG (Fig. $8 \mathrm{H}$ ), while the other one innervated the dorsomedial and dorsolateral thoracic ganglion (Fig. 8F,G). tVPM3 also arborized in the basal protocerebrum (bp; arrow, Fig. 8G).

The VPM cell type of the neuromere a1 (aVPM1; Fig. $81-\mathrm{L})$ showed a very similar innervation pattern as its $\mathrm{t} 3$ homolog. It arborized in the contralateral medial and lateral dorsal neuropil of $\mathrm{t} 2$ and $\mathrm{t} 3$ (Fig. 8J). Ventrally, the secondary neurite ran anteriorly establishing short ramifications in the thoracic ganglion (Fig. 8K). In contrast to tVPM2 and tVPM3, aVPM1 did not seem to innervate the SOG, but passed straight through it to reach the basal protocerebrum (arrow, Fig. 8I,L).

\section{DISCUSSION}

$O A$ and TA are involved in the regulation of numerous physiological and behavioral functions

Biogenic amines are important neuroactive molecules in the CNS of both vertebrates and invertebrates. Physiologically, they can act as neurotransmitters, neuromodulators or neurohormones (reviewed in Blenau and Baumann, 2001; Roeder, 2005). OA and TA were shown to regulate a broad variety of physiological functions and 

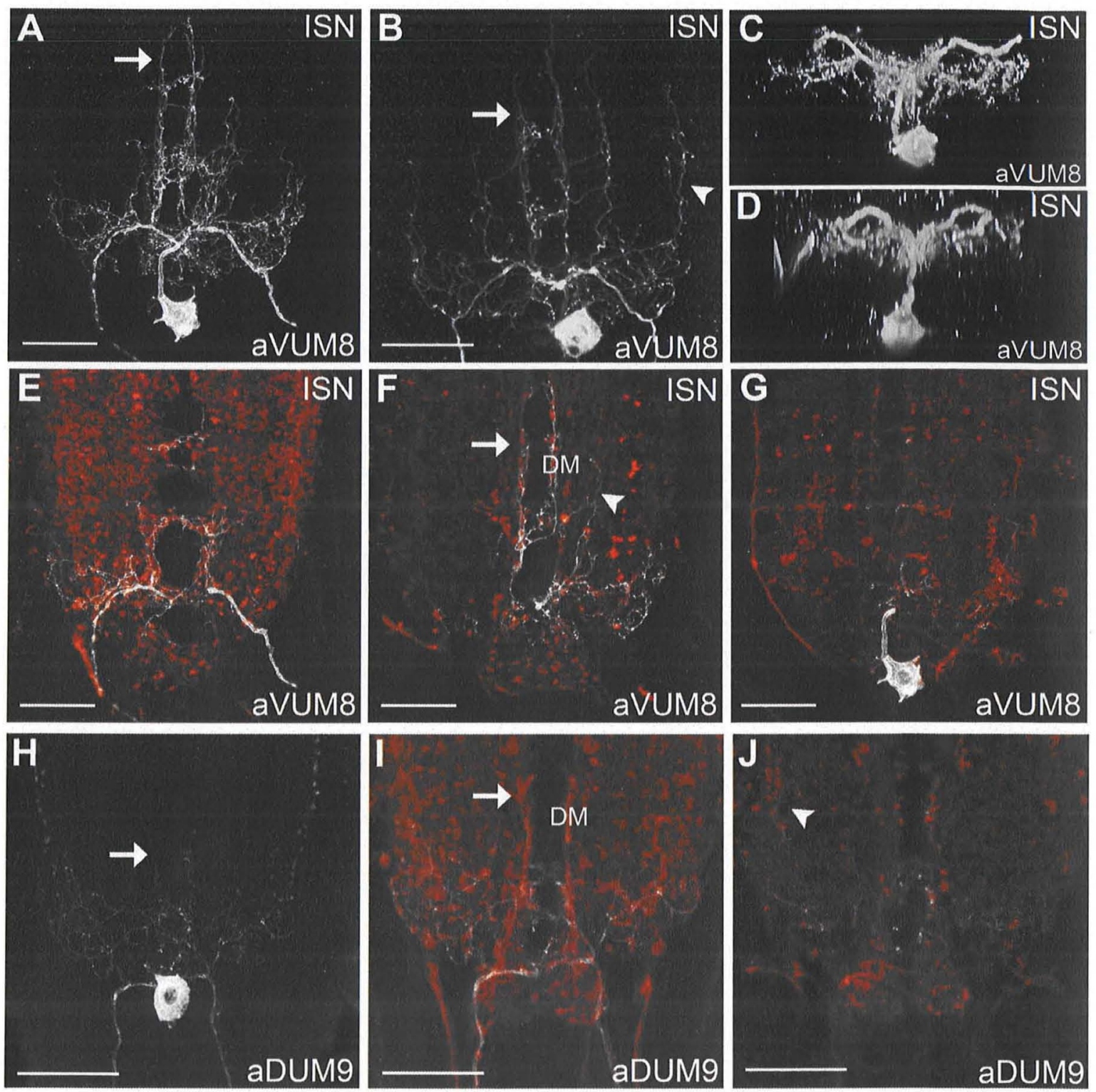

Figure 7. Anatomy of single VUM and DUM neurons of larval abdominal neuromeres a8 and a9. Horizontal projections of single VUM $(A, B)$ and DUM neurons $(H)$, respectively. Processes arborize in the dorsomedial neuropil of anterior neuromeres (arrows). C,D: Frontal view of cell projections. Dorsal up, ventral down. E-G: Different neuropil areas are innervated by the aVUM8 cell shown in A. E: Dorsal region of the VNC. The efferents project via the ISN. Ramifications along the anterior and posterior commissures of neuromeres a6, a7, and a8 are visible. $\mathrm{F}$ : The dorsomedially projecting neurites (arrow) seem to reach the posterior part of a5, while the arborizations dorsal to the central intermediate fascicle (arrowhead) end in a6. G: Ventral region of the VNC. H-J: Innervation pattern of the aDUM9 cell type. I: Ramifications in dorsal parts of neuromeres a9, a8 and a7. Neurites reaching a7 by passing dorsomedially around the dorsal median (DM) fascicle are shown (arrow). J: Neuromere a7 is also innervated by ramifications in the mediolateral neuropil (arrowhead). Scale bars $=25 \mu \mathrm{m}$.

behaviors, such as the fight-or-flight responses (Fields, 1991; Stevenson et al., 2000; Mentel et al., 2003), aggression (Stevenson et al., 2005; Hoyer et al., 2008; Zhou et al., 2008; Rillich et al., 2011), ovulation (Lee et al., 2003, 2009; Monastirioti, 2003), and flight (Brembs et al., 2007; Vierk et al., 2009).
Here we demonstrate that $\approx 42 \mathrm{OA} / \mathrm{TA}$-containing neurons in the VNC of the Drosophila larva control the modulation of locomotion, confirming earlier studies which showed that OA and TA are involved in insect locomotion (Sombati and Hoyle, 1984; Saudou et al., 1990; Arakawa et al., 1990; Yellman et al., 1997; Kutsukake et al., 2000; 

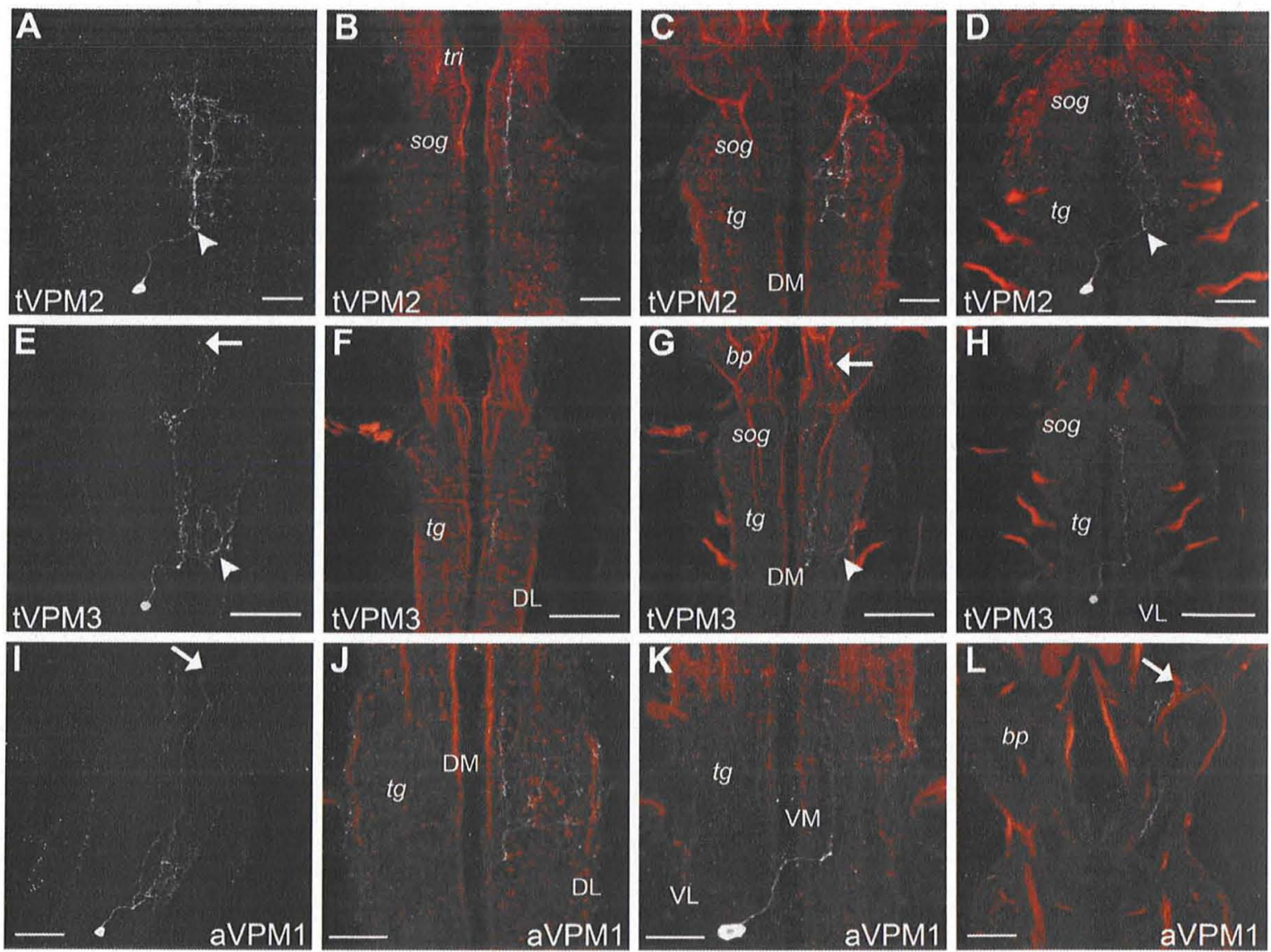

Figure 8. Anatomy of single VPM neurons of the larval VNC. A-L: Horizontal projection pattern of single octopaminergic/tyraminergic VPM neurons of the t2-a1 neuromeres. White: Tdc2-Gal4; UAS-mCD8::GFP, anti-GFP; orange: anti-ChAT/anti-Fasll. The first column shows the mostly contralateral projection of the whole cell in the CNS, the other columns show areas of specific interest. A-D: The anatomy of the tVPM2 cell. B: It arborizes in the dorsalmost parts of the medial SOG and tritocerebrum (tri). C: Bifurcations in the medial SOG and first thoracic ganglion (tg) are visualized. D: The primary neurite of tVPM2 projects contralaterally. It splits (arrowhead) and its arbors innervate the ventromedial tg and SOG. E-H: The innervation pattern of the tVPM3 cell. E,G: The neuron projects into the basal protocerebrum (bp; arrows) and to the lateral edge of the tg (arrowheads). F: It establishes ramifications in the dorsal tg and $(\mathrm{H})$ in the ventral tg and SOG. I-L: The anatomy of the aVPM1 cell. J: It branches in the dorsal contralateral tg. K: In all VPM neurons the primary neurite projects anteriorly and crosses the midline to innervate the contralateral VNC. L: aVPM1 innervates the bp (arrow). DL, dorsal lateral fascicle; DM, dorsal median fascicle; VL, ventral lateral fascicle; VM, ventral median fascicle. Scale bars $=$ A-I $50 \mu \mathrm{m}, J-L 25 \mu \mathrm{m}$.

Nagaya et al., 2002; Saraswati et al., 2004; Fox et al., 2006). The role of neuromodulators was initially explained by an "orchestration hypothesis," which assumed that neuromodulator release into specific neuropils configures distinct neural assemblies to produce coordinated network activity (Sombati and Hoyle, 1984). However, recent work from Drosophila larval motor behavior suggests that the chemical codes producing specific motor outputs are bouquets of different amines rather than single ones (Saraswati et al., 2004; Fox et al., 2006). Thus, to understand the mixture of different amines it is important to trace individual aminergic cells as well as the location of the related receptors. By describing the innervation pattern of single Tdc2-Gal4--positive neurons in the larval VNC we provide the basis for studying the molecular organization of $O A$ and TA on the single-cell level. In detail, three different types of OA/TA cells exist (Vömel and Wegener, 2008; this study): VUM, DUM, and VPM neurons. While the latter are restricted to the CNS, VUM and DUM cells project additionally to the periphery.

\section{Octopaminergic and tyraminergic neurons in the ventral nerve cord are necessary for larval locomotion}

Regarding the role of octopaminergic/tyraminergic neurons in larval locomotion, it was shown that TRH mutant larvae with elevated TA levels and reduced OA levels 

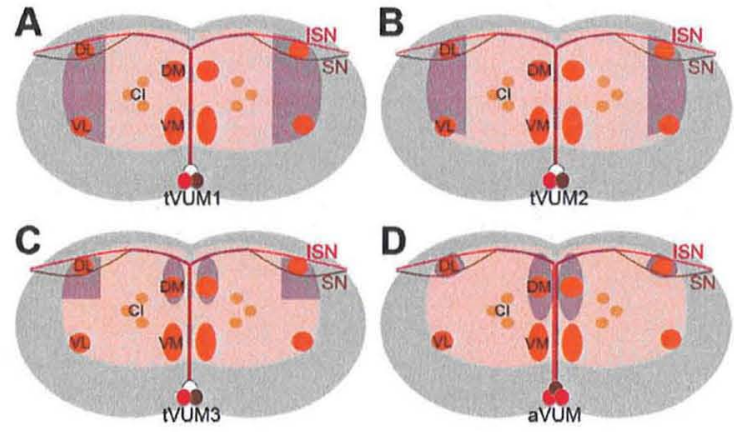

Figure 9. Schematic drawing of the VUM neurons in the thoracic and abdominal neuromeres. A-D: Transverse sections of the first $(A)$, second $(B)$, third $(C)$ thoracic, and an abdominal (D) neuromere (after Vömel and Wegener, 2008). Dorsal is at the top and ventral at the bottom. Fasll-positive longitudinal tracts (orange) are termed after Landgraf et al. (2003). The primary neurite of each of the three VUM neurons runs along the midline dorsally, splits in a t-shaped manner, and projects symmetrically into the peripheral nerve, either via the intersegmental nerve (ISN; red) or the segmental nerve ( $\mathrm{SN}$; brown). The area of arborization is shown in purple, the neuropil in light orange, and cortex in gray. A-C: The white cell body in each of the thoracic neuromeres indicates that the ISN or SN projection of this VUM neuron is not confirmed. V, ventral; C, central; D, dorsal; M, median; I, intermediate; L, lateral.

spent more time in pausing episodes, were slower and displayed reduced linear crawling (Saraswati et al., 2004). As this phenotype can be rescued by feeding either TA receptor antagonists or OA, both amines seem to antagonize each other in larval locomotion. In our studies, electrical silencing with UAS-Kir2.1 and genetic ablation of Tdc2-Ga/4-positive neurons with UAS-Hid,Rpr induced similar movement defects (Fig. 4). Compared to control larvae, experimental larvae crawled shorter distances per minute. Moreover, they partially showed a characteristic circling behavior, unlike wildtype larvae, which typically moved toward the edges of the Petri dish as part of their searching behavior. This is in line with previous studies, as both the circling behavior and the shorter distances traveled reflect impairments in linear crawling and speed (Saraswati et al., 2004). Interestingly, we were able to rescue this phenotype by combining $T d c 2-G a l 4$ with a tshGal80 construct (Fig. 4), whose expression inhibits Tdc2-Gal4 transcription in the VNC except for about two cells in the 11 neuromere and at least one cell each in the ventral and dorsal cluster in the last abdominal neuromeres a8 and a9, respectively (Table 2). Tdc2-Gal4;tshGal80/UAS-Hid,Rpr larvae showed normal forward movement, indicating the necessity of OA/TA cells in the VNC for locomotion and the dispensability of such cells in the brain for this behavior.
The 32 VUM cells are the major set of OA/TA neurons in the larval VNC. All of them except those in the $t 1$ and t2 neuromeres seem to contact one or several VUM cells from the corresponding clusters in at least the two anterior neuromeres (data not shown). This potential connectivity between all muscle innervating VUM neurons might be the functional basis for the peristaltic movements necessary for larval locomotion.

All VUM cells exhibit a motor neuron-like morphology, exhibiting potential postsynaptic sites in the dorsal VNC and presynaptic endings on the muscles (Monastirioti et al., 1995; Vömel and Wegener, 2008; Koon et al., 2011). VUM terminals seem to be located in the vicinity of type I boutons, in agreement with findings that VUM neurons regulate the plasticity of type I boutons (Fig. $1 \mathrm{~K})$ (Koon et al., 2011). Hence, the locomotion defect we observe in $T \beta H$ mutants and in larvae lacking OA/TA neurons in the VNC (Tdc2-Gal4/UAS-Hid,Rpr; Figs. 3, 4) might depend on the significant decrease of type I bouton numbers due to the lack of octopaminergic input (Koon et al., 2011). As normal locomotion is monitored with intact OA/TA cells in the VNC only (Tdc2-Gal4,tshGal80/UAS-Hid,Rpr; Fig. 4), OA/TA neurons of the SOG and brain are dispensable for this behavior. Therefore, we show for the first time in Drosophila larva a clear functional segregation between aminergic cells of the brain/SOG and those of the VNC.

DUM neurons do not seem to be essential for larval locomotion, as tshGal80 is not constantly expressed in them. In fact, in most Tdc2-Gal4/tshGal80;UAS-Cameleon2.1 larvae we observed Gal4 expression in at least one DUM neuron of the a9 neuromere (Fig. 4E,F; Table 2 ), indicating that Gal80 is not or only weakly expressed in these cells. The drastically reduced number of muscles in the last neuromeres a8 and a9 (Bate, 1993) is another indication for their negligible role in larval crawling. Additional neurons in the VNC that are unlikely involved in larval locomotion-because of weak or missing tshGal80 expression-are the VPM cells of neuromere t1. In all Tdc2-Gal4/tshGal80; UAS-Cameleon2.1 larvae, staining in tVPM1 cells was observed (Fig. 4E,F; Table 2). Octopaminergic/tyraminergic VPM neurons project to the SOG and to some extent also to the supraesophageal ganglion. It is possible that these paired cells send information from the thoracic ganglion to the SOG and basal protocerebrum or vice versa. VPM neurons project into more ventral regions of the VNC than VUM cells, layers showing arborizations from other cells than motor neurons. Interestingly, VPM cells were not found in neuromeres a2 to a9. Whether this cell type plays a role at all in larval locomotion has to be investigated in more detail. 


\section{Anatomy of octopaminergic/tyraminergic neurons in the ventral ganglia of Drosophila larva}

In the VNC of Drosophila larvae, octopaminergic/tyraminergic UM neurons and their projections were described by antibody staining against $\mathrm{OA}$, TA, or $\mathrm{T} \beta \mathrm{H}$ (Monastirioti, 1995, 1996, 1999; Nagaya et al., 2002) and by genetic tools using Tdc2-Gal4 (Vömel and Wegener, 2008; Koon et al., 2011). Here we show immunocytochemically that the $42 \mathrm{Tdc}$-Gal4 expressing neurons are $\mathrm{OA}$-, TA-, and TBH-positive. Whereas the OA antibody might crossreact with TA (see also Busch et al., 2009), the T $\beta H$ antibody, which recognizes the enzyme necessary for OA synthesis, seems to reliably label octopaminergic neurons (Monastirioti et al., 1996). Tyraminergic neurons can be visualized by a TA-antibody (Chemicon; see also Nagaya et al., 2002). This antibody may crossreact with $\mathrm{OA}$. However, all octopaminergic neurons should contain TA, as it is the precursor of OA. Hence, the potential crossreactivity should not yield false-positive results. Comparing the anti-T $\beta H$ staining with the anti-TA staining showed that all Tdc2-Gal4-expressing neurons are octopaminergic and tyraminergic. Potentially two TA-immunoreactive cells in neuromere 1 exist, which were never visualized by the $\mathrm{T} \beta \mathrm{H}$ antibody and in the Gal4 line (data not shown). Therefore, this immunochemical approach implies that the apparently different functions of $O A$ and TA in larval locomotion are not realized by specialized tyraminergic neurons. Unfortunately, nothing is known about the subcellular localization of OA and TA. Also, whether the same cell can use both OA and TA as modulators is not understood. Therefore, it is actually not possible to hypothesize about distinct functions of the two amines, e.g., whether they activate different targets or exert different effects on the same target.

The VNC of Drosophila larvae comprises three VUM neurons per neuromere (except for neuromeres a 8 and a9). The efferent abdominal VUMs are known to innervate nearly all body wall muscles of their segment via type II boutons (Monastirioti et al., 1995; Hoang and Chiba, 2001; Koon et al., 2011). By single-cell staining we found two types of octopaminergic/tyraminergic VUM neurons, based on the route taken by their efferent neurites to enter the peripheral nerve. Apart from this marginal discrepancy, it seems that all VUM neurons of a given neuromere are distinct by the muscles they innervate (this study). In about 500 preparations showing either a single or several distinct labeled VUM neurons different overall neuropil arborization patterns were never observed. Although subtle interindividual variations exist (Figs. 5, 6), the general characteristics remain the same. Nevertheless, this does not necessarily mean that the cells are the same, as we could not tell anything about their connec- tions to other neurons in this neuropil region. Also, despite our analysis of about 500 larval preparations, we cannot rule out the presence of an additional type of VUM neuron.

\section{VUM and DUM neurons in the ventral ganglia of insects}

UM cells are known from many different insects like flies, locusts, crickets, cockroaches, honeybees, stick insects, silkmoths and hawkmoths (Taylor, 1974; Casaday, 1976; Davis, 1977; Hoyle, 1978; Davis, 1979; Rheuben and Kammer, 1980; Christensen, 1981; Kondoh, 1982; Christensen et al., 1983; Arikawa et al., 1984; Brookes, 1988; Pflüger and Watson, 1988; Ferber and Pflüger, 1990; Pflüger et al., 1993; Hammer, 1993; Sinakevitch et al., 1995; Monastirioti, 1999; Schröter et al., 2007; Mentel et al., 2008; Busch et al., 2009; Goldammer et al., 2011). It was shown that most of the UM cells of the VNC extend their efferents bilaterally symmetrical to the peripheral nerves. UM neurons are thought to play a role in the control of muscles in all of these insects (Brookes, 1988; Ferber and Pflöger, 1990; Pflöger et al., 1993; Johnston et al., 1999; Nishikawa and Kidokoro, 1999; Nagaya et al., 2002; Dasari and Cooper, 2004; Koon et al., 2011).

In adult Drosophila OA-immunoreactive cells were described at the ventral midline in all thoracic and the fused abdominal neuromeres (Monastirioti et al., 1995). Given that single-cell stainings are lacking for the adult VNC, it is not possible to tell whether VPM neurons also exist. However, in the published reports of OA-immunoreactivity and $T d c 2-\mathrm{Ga} / 4$ expression patterns, neurons with smaller cell bodies are visible next to the midline (Monastirioti et al., 1995; Cole et al., 2005). Apart from the innervation of the ovaries by the octopaminergic/tyraminergic neurons via the abdominal nerve to the ovary, not much is known about the projection patterns of the $\approx 18 \mathrm{VM}$ cells in the VNC (Monastirioti, 2003; Cole et al., 2005; Rodriguez-Valentin et al., 2006). Prothoracic cervical muscles were shown to be innervated by type II boutons containing OA, potentially from VUM neurons of the VNC (Rivlin et al., 2004). Interestingly, electrophysiological studies provided evidence that OA affects leg muscle function in adult flies (Dudai, 1987). In line with this observation, $\mathrm{OA}$ also seems to modulate escape jumping (Zumstein et al., 2004; Harvey et al., 2008). In other insects, leg-innervating DUM neurons with potential roles in motor behavior were described (Theophilidis, 1983; Gras, 1990; Burrows and Pflüger, 1995; Baudoux et al., 1998; Mentel et al., 2008). The application of OA to the nerve cord of decapitated flies stimulated locomotion and grooming (Yellman et al., 1997), suggesting a modulatory 
role of $\mathrm{OA}$ also in adult locomotion. Because no singlecell analysis of octopaminergic/tyraminergic cells in the adult VNC is available, not to mention any investigation of their properties during the transition from larvae to adults, a comparison between the developmental stages is currently not feasible.

In Antheraea pernyi larvae two bilaterally symmetrical projecting neurons with medial cell bodies in the abdominal ganglia 3, 4, 5, and 6 were described (MC1 and MC2) (Brookes, 1988). The innervation pattern of each of the two cells in the abdominal neuropil appeared to be indistinguishable. Their primary neurites extend together before splitting. Then the secondary processes project along the dorsal surface of the neuropil to pass into the nerve of the corresponding side. The only difference between the two cells appear to be their peripheral innervation (Brookes and Weevers, 1988). This characteristic projection pattern of UM neurons is also observed in Drosophila larva (Figs. 1C, $5,6)$. In Manduca sexta larvae, three OA-immunoreactive VUM neurons per thoracic ganglion and two OAimmunoreactive VUM cells per abdominal ganglion were described (Pflüger et al., 1993). These authors were able to show that both cells of the abdominal ganglia symmetrically leave the VNC through the dorsal nerves (DN) of their neuromere. Again, they differ with respect to the muscles they innervated as they extend through different branches of the DN (Pflüger et al., 1993). For both $A$. pernyi and Manduca larvae, no obvious difference in the projection patterns of the VUM neurons in the abdominal neuropil was observed (Brookes, 1988; Pflüger et al., 1993), observations we can confirm for the Drosophila larva. Hence, it seems that even though the number of UM cells varies between these three types of larvae, their overall characteristics remain the same.

\section{ACKNOWLEDGMENT}

The authors thank Simon Sprecher, Maria Monastirioti, Gary Struhl, Julie Simpson, and Erich Buchner for flies or antibodies and Christian Wegener, Nanae Gendre, and Simon Sprecher for technical assistance and/or comments on the article.

\section{Author contributions}

Conceived and designed the experiments: M.S., D.P., R.F.S, A.S.T.; Performed the experiments: M.S., D.P.; Analyzed the data: M.S., D.P., B.eJ., R.F.S., A.S.T.; Wrote the article: M.S., D.P., B.eJ., R.F.S., A.S.T.

\section{LITERATURE CITED}

Arakawa S, Gocayne JD, McCombie WR, Urquhart DA, Hall LM, Fraser CM, Venter JC. 1990. Cloning, localization, and permanent expression of a Drosophila octopamine receptor. Neuron 4:343-354.

Arikawa K, Washio H, Tanaka Y. 1984. Dorsal unpaired median neurons of the cockroach metathoracic ganglion. J Neurobiol 15:531-536.

Baier A, Wittek B, Brembs B. 2002. Drosophila as a new model organism for the neurobiology of aggression? J Exp Biol 205(Pt 9): 1233-1240.

Baines RA, Uhler JP, Thompson A, Sweeney ST, Bate M. 2001. Altered electrical properties in Drosophila neurons developing without synaptic transmission. J Neurosci 21: 1523-1531.

Bate M. 1993. The mesoderm and its derivatives. In: A Bate M., A. Martinez Arias, editor. The development of Drosophila melanogaster. Cold Spring Harbor, NY: Cold Spring Harbor Laboratory Press. p 1013-1090.

Baudoux S, Duch C, Morris OT. 1998. Coupling of efferent neuromodulatory neurons to rhythmical leg motor activity in the locust. J Neurophysiol 79:361-370.

Blenau W, Baumann A. 2001. Molecular and pharmacological properties of insect biogenic amine receptors: lessons from Drosophila melanogaster and Apis mellifera. Arch Insect Biochem Physiol 48:13-38.

Brand AH, Perrimon N. 1993. Targeted gene expression as a means of altering cell fates and generating dominant phenotypes. Development 118:401-415.

Bräunig P. 1991. Suboesophageal DUM neurons innervate the principal neuropiles of the locust brain. Philos Trans R Soc Lond B 332:221-240.

Brembs B, Christiansen F, Pflüger HJ, Duch C. 2007. Flight initiation and maintenance deficits in flies with genetically altered biogenic amine levels. J Neurosci 27: 11122-11131.

Brookes SJH, Weevers RG. 1988. Unpaired median neurones in a lepidopteran larva (Antheraea pernyi) I. Anatomy and physiology. J Exp Biol 136:311-332.

Burrows M, Pflüger HJ. 1995. Action of locust neuromodulatory neurons is coupled to specific motor patterns. I Neurophysiol 74:347-357.

Busch S, Selcho M, Ito K, Tanimoto H. 2009. A map of octopaminergic neurons in the Drosophila brain. J Comp Neurol 513:643-667.

Campos-Ortega JA, Hartenstein V. 1997. The embryonic development of Drosophila melanogaster. Berlin: Springer.

Casaday GB, Camhi JM. 1976. Metamorphosis of flight motor neurons in the moth Manduca sexta. J Comp Physiol 112: 143-158.

Certel SJ, Savella MG, Schlegel DC, Kravitz EA. 2007. Modulation of Drosophila male behavioral choice. Proc Natl Acad Sci U S A 104:4706-4711.

Christensen TA, Sherman TG, McCaman RE, Carlson AD. 1983. Presence of octopamine in firefly photomotor neurons. Neuroscience 9:183-189.

Christensen TAJ, Carlson AD. 1981. Symmetrically organised dorsal unpaired median (DUM) neurones and flash control in the male firefly Photuris versicolo. J Exp Biol 93: 133-147.

Clyne JD, Miesenböck G. 2008. Sex-specific control and tuning of the pattern generator for courtship song in Drosophila. Cell 133:354-363.

Cole SH, Carney GE, McClung CA, Willard SS, Taylor BJ, Hirsh J. 2005. Two functional but noncomplementing Drosophila tyrosine decarboxylase genes: distinct roles for neural tyramine and octopamine in female fertility. J Biol Chem 280: 14948-14955.

Crocker A, Shahidullah M, Levitan IB, Sehgal A. 2010. Identification of a neural circuit that underlies the effects of octopamine on sleep:wake behavior. Neuron 65:670-681. 
Dasari S, Cooper RL. 2004. Modulation of sensory-CNS-motor circuits by serotonin, octopamine, and dopamine in semiintact Drosophila larva. Neurosci Res 48:221-227.

Davis NT. 1977. Motor neurons of the indirect flight muscle of Dysdercus fulvoniger. Ann Entymol Soc Am 70:377-386.

Davis NT, Alanis J. 1979. Morphological and electrophysiological characteristics of a dorsal unpaired median neuron of the cricket Acheta domesticus. Comp Biochem Physiol 62A:777-788

Diegelmann S, Fiala A, Leibold C, Spall T, Buchner E. 2002. Transgenic flies expressing the fluorescence calcium sensor Cameleon 2.1 under UAS control. Genesis 34:95-98.

Dudai Y, Buxbaum J, Corfas G, Ofarim M. 1987. Formamidines interact with Drosophila octopamine receptors, alter the flies' behavior and reduce their learning ability. J Comp Physiol A 161:739-746.

Evans PD. 1984. A modulatory octopaminergic neurone increases cyclic nucleotide levels in locust skeletal muscle. J Physiol 348:307-324.

Evans PD, O'Shea M. 1977. An octopaminergic neurone modulates neuromuscular transmission in the locust. Nature 270:257-259.

Farooqui T. 2007. Octopamine-mediated neuromodulation of insect senses. Neurochem Res 32:1511-1529.

Ferber M, Pflüger HJ. 1990. Bilaterally projecting neurones in pregenital abdominal ganglia of the locust: anatomy and peripheral targets. J Comp Neurol 302:447-460.

Fields PE, Woodring JP. 1991. Octopamine mobilization of lipids and carbohydrates in the house cricket, Acheta domesticus. J Insect Physiol 37:193-199.

Fox LE, Soll DR, Wu CF. 2006. Coordination and modulation of locomotion pattern generators in Drosophila larvae: effects of altered biogenic amine levels by the tyramine beta hydroxlyase mutation. J Neurosci 26:1486-1498.

Geffard M, Seguela P, Heinrich-Rock AM. 1984. Antisera against catecholamines: specificity studies and physicochemical data for anti-dopamine and anti-p-tyramine antibodies. Mol Immunol 21:515-522.

Godenschwege TA, Reisch D, Diegelmann S, Eberle K, Funk N, Heisenberg M, Hoppe V, Hoppe J, Klagges BR, Martin JR, Nikitina EA, Putz G, Reifegerste R, Reisch N, Rister J, Schaupp M, Scholz H, Schwärzel M, Werner U, Zars TD, Buchner S, Buchner E. 2004. Flies lacking all synapsins are unexpectedly healthy but are impaired in complex behaviour. Eur J Neurosci 20:611-622.

Goldammer J, Buschges A, Schmidt J. 2011. Motoneurons, DUM cells, and sensory neurons in an insect thoracic ganglion: a tracing study in the stick insect Carausius morosus. J Comp Neurol 520:Spc 1.

Gramates LS, Budnik V. 1999. Assembly and maturation of the Drosophila larval neuromuscular junction. Int Rev Neurobiol 43:93-117.

Gras H, Hörner M, Runge L, Schürmann F-W. 1990. Prothoracic DUM neurons of the cricket Gryllus bimaculatus. Responses to natural stimuli and activity in walking behavior. J Comp Physiol A 166:901-914.

Grenningloh G, Rehm EJ, Goodman CS. 1991. Genetic analysis of growth cone guidance in Drosophila: fasciclin II functions as a neuronal recognition molecule. Cell 67:45-57.

Grether ME, Abrams JM, Agapite J, White K, Steller H. 1995. The head involution defective gene of Drosophila melanogaster functions in programmed cell death. Genes Dev 9:1694-1708.

Hammer M. 1993. An identified neuron mediates the unconditioned stimulus in associative olfactory learning in honeybees. Nature 366:59-63.

Hammer M, Menzel R. 1998. Multiple sites of associative odor learning as revealed by local brain microinjections of octopamine in honeybees. Learn Mem 5:146-156.
Hardie SL, Zhang JX, Hirsh J. 2007. Trace amines differentially regulate adult locomotor activity, cocaine sensitivity, and female fertility in Drosophila melanogaster. Dev Neurobiol 67:1396-1405.

Harvey J, Brunger H, Middleton CA, Hill JA, Sevdali M, Sweeney ST, Sparrow JC, Elliott CJ. 2008. Neuromuscular control of a single twitch muscle in wild type and mutant Drosophila, measured with an ergometer. Invert Neurosci 8:63-70.

Hay BA, Wassarman DA, Rubin GM. 1995. Drosophila homologs of baculovirus inhibitor of apoptosis proteins function to block cell death. Cell 83:1253-1262.

Hoang B, Chiba A. 2001. Single-cell analysis of Drosophila larval neuromuscular synapses. Dev Biol 229:55-70.

Homyk T, Sheppard DE. 1977. Behavioral mutants of Drosophila melanogaster. I. Isolation and mapping of mutations which decrease flight ability. Genetics 87:95-104.

Hoyer SC, Eckart A, Herrel A, Zars T, Fischer SA, Hardie SL, Heisenberg M. 2008. Octopamine in male aggression of Drosophila. Curr Biol 18:159-167.

Hoyle G. 1978. The dorsal, unpaired, median neurons of the locust metathoracic ganglion. J Neurobiol 9:43-57.

Jan LY, Jan YN. 1976. L-glutamate as an excitatory transmitter at the Drosophila larval neuromuscular junction. J Physiol 262:215-236

Johansen J, Halpern ME, Johansen KM, Keshishian H. 1989. Stereotypic morphology of glutamatergic synapses on identified muscle cells of Drosophila larvae. J Neurosci 9: 710-725.

Johnston RM, Consoulas C, Pflüger H, Levine RB. 1999. Patterned activation of unpaired median neurons during fictive crawling in manduca sexta larvae. J Exp Biol 202(Pt 2): 103-113.

Klagges BR, Heimbeck G, Godenschwege TA, Hofbauer A, Pflugfelder GO, Reifegerste R, Reisch D, Schaupp M, Buchner S, Buchner E. 1996. Invertebrate synapsins: a single gene codes for several isoforms in Drosophila. J Neurosci 16:3154-3165.

Kondoh Y, Obara Y. 1982. Anatomy of motoneurones innervating mesothoracic indirect flight muscles in the silkmoth Bombyx mori. J Exp Biol 98:23-38.

Kononenko NL, Wolfenberg H, Pflüger HJ. 2009. Tyramine as an independent transmitter and a precursor of octopamine in the locust central nervous system: an immunocytochemical study. J Comp Neurol 512:433-452.

Koon AC, Ashley J, Barria R, DasGupta S, Brain R, Waddell S, Alkema MJ, Budnik V. 2011. Autoregulatory and paracrine control of synaptic and behavioral plasticity by octopaminergic signaling. Nat Neurosci 14:190-199.

Kurada P, White K. 1998. Ras promotes cell survival in Drosophila by downregulating hid expression. Cell 95:319-329.

Kutsukake M, Komatsu A, Yamamoto D, Ishiwa-Chigusa S. 2000. A tyramine receptor gene mutation causes a defective olfactory behavior in Drosophila melanogaster. Gene 245:31-42.

Lahiri S, Shen K, Klein M, Tang A, Kane E, Gershow M, Garrity $P$, Samuel AD. 2011. Two alternating motor programs drive navigation in Drosophila larva. PLoS One 6:e23180.

Landgraf M, Bossing T, Technau GM, Bate M. 1997. The origin, location, and projections of the embryonic abdominal motorneurons of Drosophila. J Neurosci 17:9642-9655.

Landgraf M, Sanchez-Soriano N, Technau GM, Urban J, Prokop A. 2003. Charting the Drosophila neuropile: a strategy for the standardised characterisation of genetically amenable neurites. Dev Biol 260:207-225.

Lee T, Luo L. 1999. Mosaic analysis with a repressible cell marker for studies of gene function in neuronal morphogenesis. Neuron 22:451-461. 
Lee HG, Seong CS, Kim YC, Davis RL, Han KA. 2003. Octopamine receptor OAMB is required for ovulation in Drosiophila melanogaster. Dev Biol 264:179-190.

Lee HG, Rohila S, Han KA. 2009. The octopamine receptor OAMB mediates ovulation via $\mathrm{Ca} 2+/$ calmodulin-dependent protein kinase II in the Drosophila oviduct epithelium. PLoS One 4:e4716.

Martin JR, Ernst R, Heisenberg M. 1998. Mushroom bodies suppress locomotor activity in Drosophila melanogaster. Learn Mem 5:179-191.

Mathew D, Popescu A, Budnik V. 2003. Drosophila amphiphysin functions during synaptic Fasciclin II membrane cycling. J Neurosci 23:10710-10716.

Mentel T, Duch C, Stypa H, Wegener G, Muller U, Pflüger HJ. 2003. Central modulatory neurons control fuel selection in flight muscle of migratory locust. J Neurosci 23:1109-1113.

Mentel T, Weiler V, Buschges A, Pflüger HJ. 2008. Activity of neuromodulatory neurones during stepping of a single insect leg. J Insect Physiol 54:51-61.

Michels B, Diegelmann S, Tanimoto H, Schwenkert I, Buchner E, Gerber B. 2005. A role for Synapsin in associative learning: the Drosophila larva as a study case. Learn Mem 12: 224-231.

Monastirioti M. 1999. Biogenic amine systems in the fruit fly Drosophila melanogaster. Microsc Res Tech 45:106-121.

Monastirioti M. 2003. Distinct octopamine cell population residing in the CNS abdominal ganglion controls ovulation in Drosophila melanogaster. Dev Biol 264:38-49.

Monastirioti M, Gorczyca M, Rapus J, Eckert M, White K, Budnik V. 1995. Octopamine immunoreactivity in the fruit fly Drosophila melanogaster. J Comp Neurol 356:275-287.

Monastirioti M, Linn CE Jr, White K. 1996. Characterization of Drosophila tyramine beta-hydroxylase gene and isolation of mutant flies lacking octopamine. J Neurosci 16: 3900-3911.

Mons N, Geffard M. 1987. Specific antisera against the catecholamines: L-3,4-dihydroxyphenylalanine, dopamine, noradrenaline, and octopamine tested by an enzyme-linked immunosorbent assay. J Neurochem 48:1826-1833.

Nagaya Y, Kutsukake M, Chigusa SI, Komatsu A. 2002. A trace amine, tyramine, functions as a neuromodulator in Drosophila melanogaster. Neurosci Lett 329:324-328.

Nässel DR, Winther AM. 2010. Drosophila neuropeptides in regulation of physiology and behavior. Prog Neurobiol 92: 42-104.

Nishikawa K, Kidokoro Y. 1999. Octopamine inhibits synaptic transmission at the larval neuromuscular junction in Drosophila melanogaster. Brain Res 837:67-74.

O'Dell KM. 1993. The effect of the inactive mutation on longevity, sex, rhythm and resistance to p-cresol in Drosophila melanogaster. Heredity 70(Pt 4):393-399.

O'Dell K, Burnet B. 1988. The effects on locomotor activity and reactivity of the hypoactive and inactive mutations of Drosophila melanogaster. Heredity 61:199-207.

Pflüger HJ, Watson AH. 1988. Structure and distribution of dorsal unpaired median (DUM) neurones in the abdominal nerve cord of male and female locusts. J Comp Neurol 268:329-345.

Pflüger HJ, Witten JL, Levine RB. 1993. Fate of abdominal ventral unpaired median cells during metamorphosis of the hawkmoth, Manduca sexta. J Comp Neurol 335:508-522.

Python F, Stocker RF. 2002. Immunoreactivity against choline acetyltransferase, gamma-aminobutyric acid, histamine, octopamine, and serotonin in the larval chemosensory system of Drosophila melanogaster. J Comp Neurol 453: 157- 167 .

R Development Core Team. 2011. R: a language and environment for statistical computing. ISBN 3-900051-07-0.
Rheuben MB, Kammer AE. 1980. Comparison of slow larval and fast adult muscle innervated by the same motor neurone. J Exp Biol 84:103-118.

Rillich J, Schildberger K, Stevenson PA. 2011. Octopamine and occupancy: an aminergic mechanism for intruder-resident aggression in crickets. Proc Biol Sci 278:1873-1880.

Rivlin PK, St Clair RM, Vilinsky I, Deitcher DL. 2004. Morphology and molecular organization of the adult neuromuscular junction of Drosophila. J Comp Neurol 468:596-613.

Rodriguez-Valentin R, Lopez-Gonzalez I, Jorquera R, Labarca P, Zurita M, Reynaud E. 2006. Oviduct contraction in Drosophila is modulated by a neural network that is both, octopaminergic and glutamatergic. J Cell Physiol 209:183-198.

Roeder T. 1999. Octopamine in invertebrates. Prog Neurobiol 59:533-561.

Roeder T. 2005. Tyramine and octopamine: ruling behavior and metabolism. Annu Rev Entomol 50:447-477.

Roeder T, Seifert M, Kahler C, Gewecke M. 2003. Tyramine and octopamine: antagonistic modulators of behavior and metabolism. Arch Insect Biochem Physiol 54:1-13.

Saraswati S, Fox LE, Soll DR, Wu CF. 2004. Tyramine and octopamine have opposite effects on the locomotion of Drosophila larvae. J Neurobiol 58:425-441.

Saudou F, Amlaiky N, Plassat JL, Borrelli E, Hen R. 1990. Cloning and characterization of a Drosophila tyramine receptor. EMBO J 9:3611-3617.

Scholz H. 2005. Influence of the biogenic amine tyramine on ethanol-induced behaviors in Drosophila. J Neurobiol 63: 199-214.

Scholz H, Franz M, Heberlein U. 2005. The hangover gene defines a stress pathway required for ethanol tolerance development. Nature 436:845-847.

Schroll C, Riemensperger T, Bucher D, Ehmer J, Voller T, Erbguth K, Gerber B, Hendel T, Nagel G, Buchner E, Fiala A. 2006. Light-induced activation of distinct modulatory neurons triggers appetitive or aversive learning in Drosophila larvae. Curr Biol 16:1741-1747.

Schröter U, Malun D, Menzel R. 2007. Innervation pattern of suboesophageal ventral unpaired median neurones in the honeybee brain. Cell Tissue Res 327:647-667.

Schüpbach T, Wieschaus E. 1991. Female sterile mutations on the second chromosome of Drosophila melanogaster. II. Mutations blocking oogenesis or altering egg morphology. Genetics 129:1119-1136.

Schwärzel M, Monastirioti M, Scholz H, Friggi-Grelin F, Birman S, Heisenberg M. 2003. Dopamine and octopamine differentiate between aversive and appetitive olfactory memories in Drosophila. J Neurosci 23:10495-10502.

Selcho M, Pauls D, Han KA, Stocker RF, Thum AS. 2009. The role of dopamine in Drosophila larval classical olfactory conditioning. PLoS One 4:e5897.

Shiga Y, Tanaka-Matakatsu M, Hayashi S. 1996. A nuclear GFP beta-galactosidase fusion protein as a marker for morphogenesis in living Drosophila. Dev Growth Differ 38:99-106.

Sinakevitch I, Strausfeld NJ. 2006. Comparison of octopamine-like immunoreactivity in the brains of the fruit fly and blow fly. J Comp Neurol 494:460-475.

Sinakevitch I, Geffard M, Pelhate M, Lapied B. 1994. Octopaminelike immunoreactivity in the dorsal unpaired median (DUM) neurons innervating the accessory gland of the male cockroach Periplaneta americana. Cell Tissue Res 276:15-21.

Sinakevitch II, Geffard M, Pelhate M, Lapied B. 1995. Octopaminergic dorsal unpaired median (DUM) neurones innervating the colleterial glands of the female cockroach Periplaneta americana. J Exp Biol 198(Pt 7):1539-1544.

Sink H. Whitington PM. 1991. Location and connectivity of abdominal motoneurons in the embryo and larva of Drosophila melanogaster. J Neurobiol 22:298-311. 
Sombati S, Hoyle G. 1984. Generation of specific behaviors in a locust by local release into neuropil of the natural neuromodulator octopamine. J Neurobiol 15:481-506.

Stevenson PA, Hofmann HA, Schoch K, Schildberger K. 2000. The fight and flight responses of crickets depleted of biogenic amines. J Neurobiol 43:107-120.

Stevenson PA, Dyakonova V, Rillich J, Schildberger K. 2005. Octopamine and experience-dependent modulation of aggression in crickets. J Neurosci 25:1431-1441.

Strauss R, Heisenberg M. 1993. A higher control center of locomotor behavior in the Drosophila brain. J Neurosci 13: 1852-1861.

Struhl G, Basler K. 1993. Organizing activity of wingless protein in Drosophila. Cell 72:527-540.

Suster ML, Karunanithi S, Atwood HL, Sokolowski MB. 2004. Turning behavior in Drosophila larvae: a role for the small scribbler transcript. Genes Brain Behav 3:273-286.

Takagawa K, Salvaterra P. 1996. Analysis of choline acetyltransferase protein in temperature sensitive mutant flies using newly generated monoclonal antibody. Neurosci Res 24:237-243.

Taylor HM, Truman, JW. 1974. Metamorphosis of the abdominal ganglion of the tobacco hornworm Manduca sexta. J Comp Physiol 90:367-388.

Theophilidis G, Burns MD. 1983. The innervation of the mesothoracic flexor tibiae muscle of the locust. J Exp Biol 105: 373-388.

Thomas JB, Bastiani MJ, Bate M, Goodman CS. 1984. From grasshopper to Drosophila: a common plan for neuronal development. Nature 310:203-207.
Varnam CJ, Strauss R, Belle JS, Sokolowski MB. 1996. Larval behavior of Drosophila central complex mutants: interactions between no bridge, foraging, and Chaser. J Neurogenet 11:99-115.

Vierk R, Pflueger HJ, Duch C. 2009. Differential effects of octopamine and tyramine on the central pattern generator for Manduca flight. J Comp Physiol A Neuroethol Sens Neural Behav Physiol 195:265-277.

Vömel M, Wegener C. 2008. Neuroarchitecture of aminergic systems in the larval ventral ganglion of Drosophila melanogaster. PLoS One 3:e1848.

Wang JW, Sylwester AW, Reed D, Wu DA, Soll DR, Wu CF. 1997. Morphometric description of the wandering behavior in Drosophila larvae: aberrant locomotion in $\mathrm{Na}+$ and $\mathrm{K}+$ channel mutants revealed by computer-assisted motion analysis. J Neurogenet 11:231-254.

Wong AM, Wang JW, Axel R. 2002. Spatial representation of the glomerular map in the Drosophila protocerebrum. Cell 109:229-241.

Yellman C, Tao H, He B, Hirsh J. 1997. Conserved and sexually dimorphic behavioral responses to biogenic amines in decapitated Drosophila. Proc Natl Acad Sci U S A 94: 4131-4136.

Zhou C, Rao Y, Rao Y. 2008. A subset of octopaminergic neurons are important for Drosophila aggression. Nat Neurosci 11:1059-1067.

Zumstein N, Forman O, Nongthomba U, Sparrow JC, Elliott CJ. 2004. Distance and force production during jumping in wild-type and mutant Drosophila melanogaster. J Exp Biol 207(Pt 20):3515-3522. 